\title{
A Migratory Northern Ungulate in the Pursuit of Spring: Jumping or Surfing the Green Wave?
}

\author{
Richard Bischof, ${ }^{1,2, *}$ Leif Egil Loe, ${ }^{1}$ Erling L. Meisingset, ${ }^{3}$ Barbara Zimmermann, ${ }^{4}$ \\ Bram Van Moorter, ${ }^{5}$ and Atle Mysterud ${ }^{2}$
}

1. Department of Ecology and Natural Resource Management, Norwegian University of Life Sciences, P.O. Box 5003, NO-1432 Aas, Norway; 2. Centre for Ecological and Evolutionary Synthesis, Department of Biology, University of Oslo, P.O. Box 1066 Blindern, NO0316 Oslo, Norway; 3. Norwegian Institute for Agricultural and Environmental Research, Tingvollgard, NO-6630 Tingvoll, Norway; 4. Faculty of Applied Ecology and Agricultural Sciences, Hedmark University College, Campus Evenstad, NO-2480 Koppang, Norway; 5. Centre for Conservation Biology, Department of Biology, Norwegian University of Science and Technology, NO-7491 Trondheim, Norway

Submitted July 20, 2011; Accepted June 8, 2012; Electronically published August 23, 2012

Online enhancements: appendixes. Dryad data: http://dx.doi.org/10.5061/dryad.3hr2c.

AвSTRACT: The forage-maturation hypothesis (FMH) states that herbivores migrate along a phenological gradient of plant development in order to maximize energy intake. Despite strong support for the FMH, the actual relationship between plant phenology and ungulate movement has remained enigmatic. We linked plant phenology (MODISnormalized difference vegetation index [NDVI] data) and space use of 167 migratory and 78 resident red deer (Cervus elaphus), using a space-time-time matrix of "springness," defined as the instantaneous rate of green-up. Consistent with the FMH, migrants experienced substantially greater access to early plant phenology than did residents. Deer were also more likely to migrate in areas where migration led to greater gains in springness. Rather than "surfing the green wave" during migration, migratory red deer moved rapidly from the winter to the summer range, thereby "jumping the green wave." However, migrants and, to a lesser degree, residents did track phenological green-up through parts of the growing season by making smaller-scale adjustments in habitat use. Despite pronounced differences in their life histories, we found only marginal differences between male and female red deer in this study. Those differences that we did detect pointed toward additional constraints on female space-use tactics, such as those posed by calving and caring for dependent offspring. We conclude that whereas in some systems migration itself is a way to surf the green wave, in others it may simply be a means to reconnect with phenological spring at the summer range. In the light of ubiquitous anthropogenic environmental change, understanding the relationship between the green wave and ungulate space use has important consequences for the management and conservation of migratory ungulates and the phenomenon of migration itself.

Keywords: NDVI, home range, plant phenology, springness, Cervus elaphus, stopover, animal movement.

\footnotetext{
* Corresponding author; e-mail: richard.bischof@umb.no.
}

Am. Nat. 2012. Vol. 180, pp. 407-424. (C) 2012 by The University of Chicago. $0003-0147 / 2012 / 18004-53200 \$ 15.00$. All rights reserved. DOI: $10.1086 / 667590$

\section{Introduction}

Seasonal migration between distinct summer and winter ranges is a widespread strategy among animals to adapt to spatiotemporal variation in resource abundance (e.g., Fryxell et al. 1988; Lundberg 1988). In ungulates living in temperate and boreal zones, the typical pattern consists of seasonal movements between winter ranges at low elevation and summer ranges at higher elevation (Brazda 1953; Festa-Bianchet 1988; Mysterud 1999) or, for coastal populations, migration to summer ranges farther inland (Albon and Langvatn 1992). Explanations of why ungulates benefit from migration can be divided into three rough categories (Bolger et al. 2008): (1) access to seasonally changing food resources (quality and/or quantity), (2) access to critically limited resources (seasonally and spatially, e.g., salt), and (3) seasonal escape from predators or parasites.

Although a complex set of factors may cause and constrain the seasonal space-use patterns we observe in animals, the forage-maturation hypothesis (FMH) features prominently among suggested drivers of seasonal migration in ungulates (Fryxell et al. 1988; Albon and Langvatn 1992; Hebblewhite et al. 2008). The FMH predicts that ungulates trade off forage quantity with forage quality in order to maximize energy intake. Seasonal differences in the timing of green-up- the period during which new and more palatable plant growth emerges - may prompt ungulates to move to areas with delayed plant phenology to have prolonged access to higher-quality forage with sufficient biomass (Hebblewhite et al. 2008). Convincing evidence has already emerged in support of a link between the FMH and migration: migratory ungulates' access to earlier-stage plant phenology can be prolonged relative to that of residents (Pettorelli et al. 2005a; Hebblewhite et 
al. 2008; Sawyer and Kauffman 2011), which leads to higher forage quality for migrants (Hebblewhite et al. 2008; Hamel et al. 2009). As a consequence of access to better forage, migrants are heavier than resident individuals (Albon and Langvatn 1992), and body condition is tightly linked with fitness components in ungulates (White 1983; Choquenot 1991; Gaillard et al. 2000).

Despite our growing understanding of factors driving migration, the way ungulates use migratory movements to respond to predictable environmental heterogeneity is still unclear. Specifically, there is a need to better understand and quantify the spatiotemporal relationship between plant phenology and the landscape-scale movement patterns of migrant herbivores, as this link may make migratory herbivores particularly vulnerable to anthropogenic environmental change. One hypothesis attempting to link plant phenology and migratory movements is the so-called green-wave hypothesis, a term first introduced in the waterfowl literature (Drent et al. 1978; Owen 1980), which it has largely remained confined to. The hypothesis refers to the migratory phenomenon whereby birds follow a wave of spring toward their summer destination, leading to the expression "surfing the green wave" (van der Graaf et al. 2006; van Wijk et al. 2012). Similar patterns of phenology tracking have now also been reported in ungulates (Sawyer and Kauffman 2011).

Sliding along with the leading edge of the green wave, thereby extending one's access to fresh growth, seems to be an energetically prudent tactic, as it ensures access to forage at its most palatable phenological stage. However, we can envision various constraints and trade-offs that may discourage or even prevent migrants from allowing themselves to be carried along with the green wave, for example, discontinuous habitat along the migration route, trade-offs with other life-history aspects such as predation and reproduction, and competition for territories and mates at the destination. There is a range of potential migration patterns in pursuit of the green wave (fig. 1). At one extreme, migrants slide smoothly across the landscape along with the leading edge of the green wave, and in doing so they can continuously exploit forage at the highest nutrition level (fig. 1A). This pattern can be found in some tropical ungulates, such as wildebeest (Connochaetes taurinus), which gradually move along with the green wave (Boone et al. 2006; Holdo et al. 2009). On the other extreme, migrants might move quickly between two main ranges, simply attempting to maximize access to high forage quality at each seasonal range but not while on the migration track (fig. 1C). Between these extremes lie an infinite number of possible green-wave pursuit patterns, one set of them represented by shorter, more or less frequent "hops" interrupted by stopovers (fig. 1B). The use of discrete stopover sites during migration has been re- ported in birds (Moore and Kerlinger 1987; Yong et al. 1998; van der Graaf et al. 2006; van Wijk et al. 2012), mammals (Cryan and Brown 2007; Sawyer and Kauffman 2011), and insects (Meitner et al. 2004; Wikelski et al. 2006).

Climate change and anthropogenic habitat alterations may change the phenological gradient exploited by migrants and thus diminish the benefits of migration or remove the incentive to migrate altogether. Therefore, the effective conservation and management of migratory populations requires an understanding of how and why animals migrate. For example, we expect movement patterns during migration to reflect whether seasonal migrants use migration corridors to exploit a more or less continuous gradient in resources or just as a means to an end, that is, reaching the summer range. The growing interest in stopover ecology and migration corridors (Warnock and Bishop 1998; Yong et al. 1998; Sawyer et al. 2009) in general is testament to their relevance for conservation of migrants and migration as a natural phenomenon. Yet most comparative studies involving migration consider the extremes, namely, the differences between migrating and remaining resident, rather than exploring variation in migration tactics. Any appropriately timed movement between two seasonal ranges differing in altitude and thus phenological development can give migrating herbivores a nutritional benefit without necessarily exploiting the full potential of the green wave. Many ungulates move long distances during migration, and, with few exceptions, it remains to be determined how closely they track plant phenology.

In this study, we quantify the spatiotemporal relationship between plant phenology and the landscape-scale movement patterns of a partially migratory northern ungulate (Mysterud et al. 2011). To do so, we develop a method for integrating satellite-derived vegetation indices (e.g., the normalized difference vegetation index [NDVI]; Pettorelli et al. 2005b) with animal relocations through a space-time-time matrix of phenology. In this matrix of resource state, one dimension represents locations occupied during sequential time steps and the second dimension represents the time series of resource state at each location. This approach allowed us to evaluate the consequences of both actual and hypothetical alternative space-use tactics. We use "springness" as the underlying quantitative measure of resource state. Because the rate of change in the NDVI has been directly linked to ungulate forage quality (Hamel et al. 2009), we define springness as the instantaneous rate of phenological green-up. We apply the approach to GPS monitoring data from 294 red deer (Cervus elaphus; 73 male, 221 female) in Norway. This study system is particularly well suited because the proportion of migrants has been reported as ranging from $38 \%$ to $100 \%$ in the seven different study regions, which 

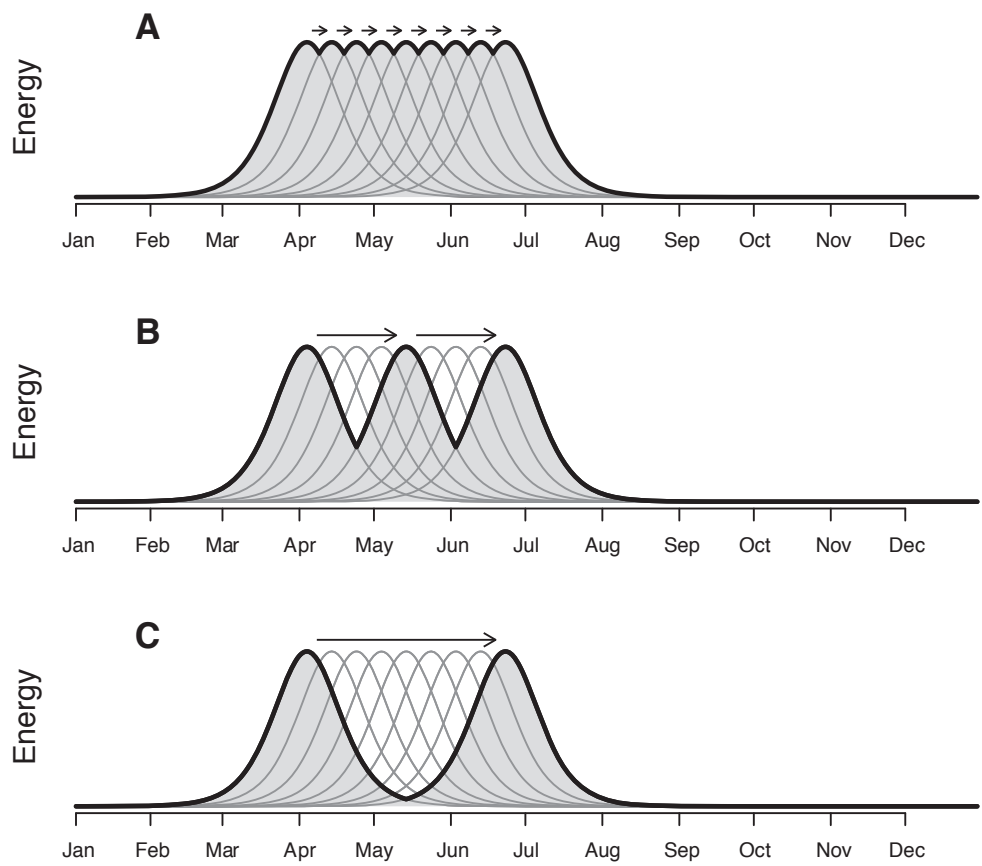

Figure 1: Schematic illustration of different migratory movement tactics (thick black lines) when confronted with the green wave, represented by snapshots of peaks in energy (nutrient) availability (thin gray lines) moving across the landscape during the growing season. Individuals surfing the green wave $(A)$ may do so by gradually sliding or moving in small spatial increments along with the wave, thereby tightly matching phenological development. Individuals jumping the green wave $(C)$, experience the passing of the green wave at one location and then transition to a new location to capture the green wave, but without sliding along its leading edge, having a considerable mismatch in speed compared to plant phenological development. Green-wave pursuit patterns depicted in $B$ are intermediate, with migrants using more or less frequent stopover sites to intersect the leading edge of the wave at different locations. Gray areas represent the cumulative "springness" experienced by migrants following each tactic.

cover a wide range of topographies (Mysterud et al. 2011). Previous studies have shown that Norwegian red deer can benefit from migration by gaining access to more palatable vegetation (Albon and Langvatn 1992; Pettorelli et al. 2005a). Here, we test a set of predictions (P1-P6) based on the FMH and the green-wave hypothesis. First, we explore whether the FMH holds as the likely explanation for migration in red deer in our study populations. If migration is a tactic to pursue the green wave, then spring should arrive later at the summer ranges of migratory red deer than at their winter ranges (P1). Migratory individuals should have greater cumulative access to springness, both in comparison with nonmigratory contemporaries (P2) and in comparison with their own access were they to remain resident (P3). Upon finding support for P1-P3, we then explore how red deer pursue the green wave. If the movements of migratory deer match the spatiotem- poral advancement of green-up (i.e., "surfing"), we expect the duration of spring migration to be comparable to the speed with which green-up advances between the winter and summer ranges (P4), whereas a migration speed faster than the speed of the green wave would signal "jumping." However, correspondence between migration speed and the speed of the green wave does not necessarily mean that red deer actually experience the leading edge of the green wave during migration (i.e., migration and greenup could still be out of synchrony in time and space). Therefore, we also test whether the phase of phenological green-up (springness) encountered by deer closely matches the peak in green-up along the migration track (P5), which we would expect if migratory deer are surfing the green wave. Finally, it is conceivable that both migratory and resident herbivores can track phenology by exploiting spatial variation in green-up through adjustments in habitat 
use within a given range (P6). If these adjustments occur at a spatial scale high enough to be picked up by the satellite-derived NDVI, phenology tracking during the growing season should be detectable in this study.

\section{Methods}

\section{Red Deer Movements}

Seven study regions cover most of the distribution range of red deer in Norway, including counties along the southwest coast (Rogaland, Hordaland, Sogn \& Fjordane, Møre \& Romsdal, and Sør-Trøndelag), as well as inland localities (Buskerud and Hedmark; fig. 2). Vegetation and climate among these regions reflect typical south-north and coastinland gradients. In general, temperature and precipitation decline from south to north and from coast to inland, while snow depth increases. Most coastal areas are occupied by deciduous forest in the south, with more coniferous forest further north and inland. The study regions are described in more detail elsewhere (e.g., Mysterud et al. 2011).

Red deer $(\geq 1.5$ years of age) were captured and marked with GPS collars (Televilt/Followit, Stockholm, Sweden; Vectronic, Berlin, Germany) during the period 2002-2010 in 68 municipalities in our seven study regions (fig. 2). Animals were darted and immobilized at sites where supplementary winter food was provided by landowners or on cultivated land along roadsides within winter areas. All marking procedures were approved by the Norwegian Animal Research Authority. The most common sampling design was to mark deer in mid- to late winter (JanuaryMarch). With a typical programmed schedule of one position every 1-2 h, the battery capacity of the GPS units theoretically allowed position sampling for up to 2 years, but mortalities, technical issues, intentional collar dropoffs, and recaptures meant that deer were, on average, monitored for 290 days ( $S D=190$ days). The collars were often retrieved in late autumn by drop-off or as part of the regular autumn hunt, allowing the same collars to be used on new individuals the next winter. The general monitoring strategy has been to monitor many individuals for a relatively short time each (one or two seasons), rather than monitoring fewer individuals over longer time periods. For this study, we had GPS data from 294 individuals (73 males, 221 females; fig. 2) monitored over a total of 353 seasons with continuous relocations (minimum of five relocations in each 16-day period) from April 1, at the latest, until August 31. The bulk of the observations (85\% of 353 monitoring seasons) come from the period 20072010 .

We know from a previous study (Mysterud et al. 2011) that red deer in our populations are partially migratory.
Migrants will typically move between low-altitude winter ranges and higher-altitude summer ranges. Resident individuals tend to stay year-round in low-elevation areas. We used the automated model-fitting approach described by Bunnefeld et al. (2011) to make initial assignments of annual deer relocation data to space-use categories. This approach fits five different functions to the profile of the net squared displacement (NSD) of sequential relocations from the origin (GPS tagging site; see Turchin 1998). The NSD pattern of a typical migrant will be hat shaped, as it moves away from the winter (marking) site in the spring, stays in one summer area for an extended period of time, and returns to the original winter site in the autumn (fig. B1, available online). Based on the best-fitting function and a set of additional criteria (see fig. B1 legend), each red deer's preliminary space-use category was designated as "migratory," "resident," or "other." The last category was for a set of relocation patterns that could not be classified as migratory or resident and included cases such as dispersal, an inconclusive seasonal movement pattern with a lack of distinct ranges, or the end of monitoring (e.g., through the animal's death) before a potential return to the winter range could be registered.

The high amount of variability in space-use patterns posed a challenge to classification. We encountered several problems with the uncritical application of the automated process by Bunnefeld et al. (2011) to our data set. Some of these problems are described in Mysterud et al. (2011) and can lead to assignment of incorrect space-use tactics or errors in the estimation of migration parameters. Therefore, although categorization was guided by the automated model-fitting approach, we based final designation on visual inspection of both net displacement (ND, i.e., net displacement between sequential relocations and a point of origin) and the spatial distribution of relocation patterns. We refitted logistic curves to the spring and fall migration segments in the ND profile to correct occasional poor fits generated during the initial automated model fitting and to account for shifts in location during the time at the summer range (i.e., deviations from the typical hatshaped ND profile). Migration parameters were then extracted from these logistic curves, with their asymptote parameter interpreted as the distance migrated, the inflection points as the midpoint of migration, and the scale value $\times 5$ as the duration of migration (fig. B2, available online). Illustrations of our approach for distinguishing movement patterns and examples of major space-use categories are shown in figures B1-B7, available online. We identified stopovers along the migration route using the approach described by Sawyer et al. (2009), by (1) employing Brownian bridge movement models to estimate the utilization distribution (probability of use) along each migration route and (2) identifying stopover sites as the 

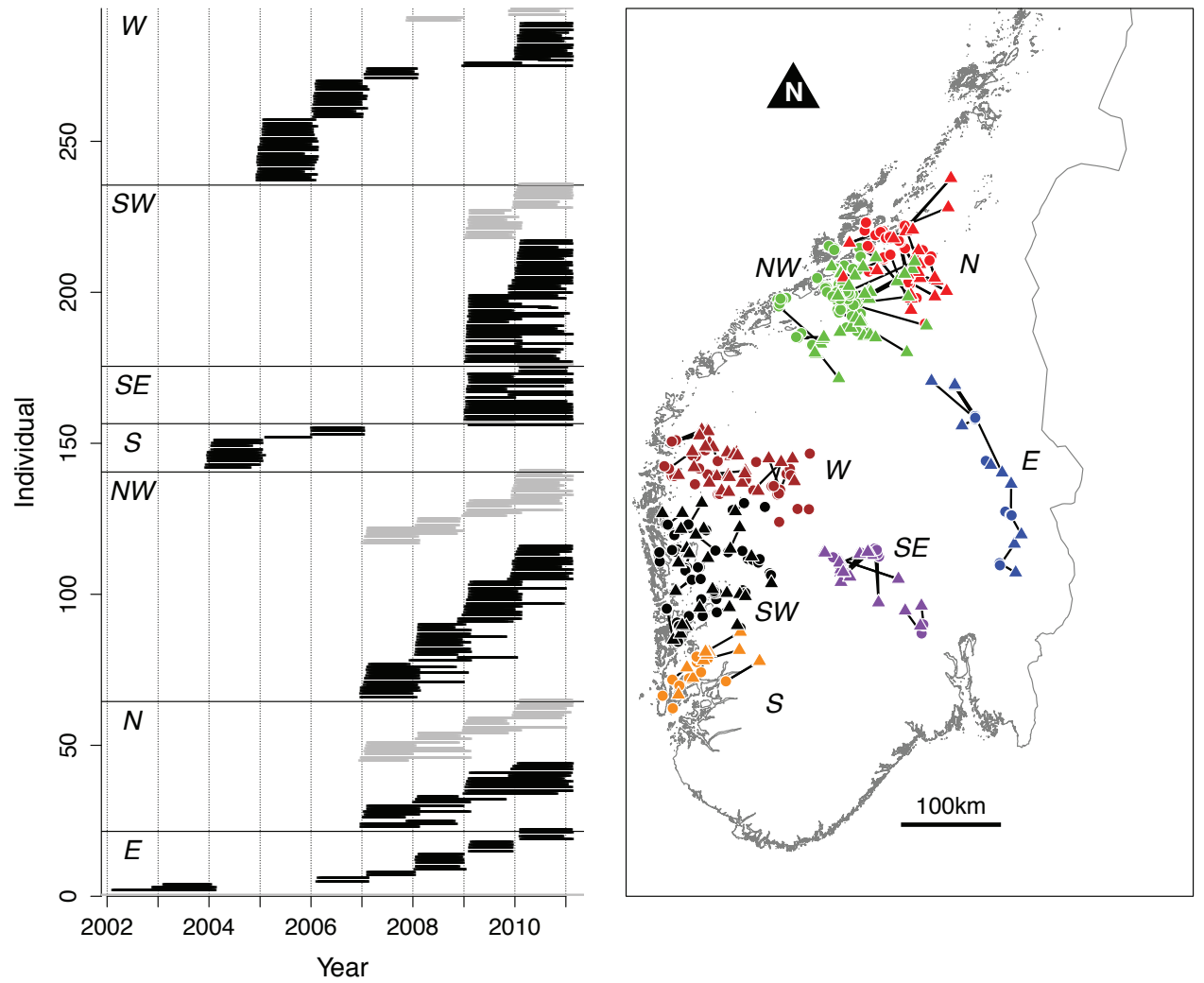

Figure 2: Monitoring history (left) and locations (right) for 294 GPS-collared red deer in Norway between 2002 and 2010. Left, each row with one or more thick horizontal segments represents one individual's GPS monitoring history (males: gray, females: black). The source areas (subpopulations) are delimited with thin horizontal lines. Right, locations of individual red deer are color coded according to study region. Winter ranges (circles) and summer ranges (triangles) of migratory individuals are connected by lines. Center locations of nonmigratory (resident) individuals are indicated with circles.

highest $25 \%$ quantile in the utilization distribution. We used the R package BBMM (Sawyer et al. 2009; Nielson et al. 2011) for stopover identification.

\section{Plant Phenology}

Satellite-derived vegetation indices, such as the NDVI, are increasingly popular among ecologists as landscape-scale measures of green biomass and seasonal changes therein (reviewed in Pettorelli et al. 2005b). The NDVI has been the measure of choice for assessing forage quality and its spatiotemporal dynamics in several recent studies exploring migration in ungulates (e.g., Hebblewhite et al. 2008;
Sawyer and Kauffman 2011). Because the NDVI closely tracks changes in plant phenology, it permits the extraction of seasonality parameters, such as the start and end of the growing season, the timing of peak biomass, and rates of green-up and dry-down (e.g., Hird and McDermid 2009).

In this study, we used MOD13Q1 images collected by NASA's MODIS TERRA satellite (http://modis.gsfc.nasa .gov/), which are made available at a dedicated FTP site (ftp://e4ft101.cr.usgs.gov/MOLT/MOD13Q1.005/). We constructed NDVI time series (based on the 16-day frequency of NDVI satellite images) for each pixel that contained red deer relocations throughout the entire study period. We then subjected these time series to a set of 
processing steps that yielded smoothed and scaled (between 0 and 1) 9-year NDVI time series for each red deer relocation site, which we further processed and analyzed using the space-time-time matrix approach described in the next section. For the extraction and processing of raw NDVI time series, we followed the approach developed by Beck et al. (2006) and fitted a double-logistic curve to the NDVI data, the method that performed best in Hird and McDermid's (2009) comparison of NDVI filtering approaches (see app. A, available online, for details).

Springness. We extracted a measure of springness throughout a calendar year for each relocation site by calculating the first derivative of the logistic function fit to the NDVI time series (green-up phase only), representing the instantaneous rate of green-up (solid line in fig. 3; eq. [A2], available online). Support for a direct link between ungulate forage quality and the rate of change in the NDVI comes from a study on mountain ungulates, which found that the timing of the steepest part of the NDVI curve (i.e., the highest positive derivative) was positively correlated with the peak in fecal crude protein (Hamel et al. 2009). We used the functional form of the rate of greenup instead of calculating the per-period rate of change in the NDVI (Hird and McDermid 2009), because several of our analyses required a temporal resolution finer than that of the 16-day composite. This instantaneous rate of greenup (IRG, scaled to between 0 and 1 ) represents an objective and quantitative measure of springness at a given time and in a given location. Importantly, this measure can be used to compare individuals and/or space-use tactics and to quantify the effect of various individual and environmental covariates on access to fresh growth, for example, by determining the cumulative IRG (CIRG) during the entire year or during some focal time period.

The satellite-derived NDVI of forested areas measures photosynthetic activity (or green biomass) of the canopy, not necessarily that of the main forage plants of red deer or other ungulates. In addition, although the NDVI can and has been used to give a landscape-scale overview of phenological patterns (e.g., Beck et al. 2006; Karlsen et al. 2006, 2008), one should use caution when comparing parameters extracted from pixels that potentially differ in topographic structure and vegetation communities (Pettorelli et al. 2005b). We interpret springness derived from the NDVI as a measure of the distance from overall peak green-up rate at a given location (facilitated by scaling both NDVI and IRG time series to between 0 and 1) rather than as a relative measure of fresh plant biomass. Furthermore, investigating elk (Cervus elaphus) forage plants in Canada, Hebblewhite et al. (2008) found that ground estimates of herbaceous biomass were correlated with the satellite-derived NDVI in tree-covered habitat and that the peaks of shrub and herbaceous growth were correlated as well.

\section{Relating Deer Movements to Plant Phenology}

Space-time-time matrix. The multidimensionality of animal space use and plant phenology dynamics make relating movement data to NDVI time series challenging (Beck et al. 2008). Our conceptual approach for testing whether red deer pursued the green wave is centered on two features. One is the definition presented above of a measure of cumulative springness experienced by individuals throughout the focal green-up period considered in this study (April 1-August 31). The other is the construction of a space-time-time matrix for each individual, combining time series of the intensity of green-up (i.e., springness) of all location clusters occupied at some time during the focal period. The space-time-time matrix relates red deer relocation data to spatiotemporal patterns in spring-

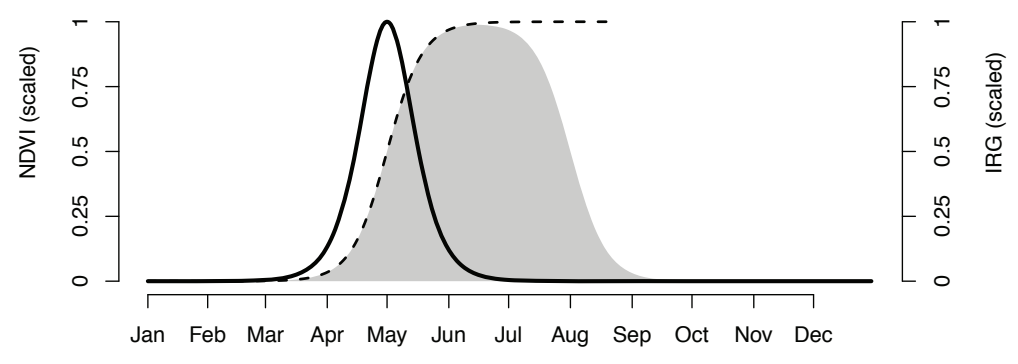

Figure 3: Schematic representation of an annual normalized difference vegetation index (NDVI) profile (gray area). A functional-form green-up is represented by a logistic curve (dashed line) fitted to the spring portion of the profile. The first derivate of the logistic curve (solid line) is the date-specific instantaneous rate of green-up (IRG), interpreted in this study as "springness." 
ness (i.e., IRG); a separate matrix is constructed for each individual red deer and year:

$$
\left[\begin{array}{cccc}
\operatorname{IRG}\left(l\left(t_{1}\right), t_{1}\right) & \operatorname{IRG}\left(l\left(t_{1}\right), t_{2}\right) & \ldots & \operatorname{IRG}\left(l\left(t_{1}\right), t_{T}\right) \\
\operatorname{IRG}\left(l\left(t_{2}\right), t_{1}\right) & \operatorname{IRG}\left(l\left(t_{2}\right), t_{2}\right) & & \\
\vdots & & \ddots & \\
\operatorname{IRG}\left(l\left(t_{T}\right), t_{1}\right) & & & \operatorname{IRG}\left(l\left(t_{T}\right), t_{T}\right)
\end{array}\right] .
$$

The rows and columns of the matrix represent spacetime (occupation time) and time (phenological time) dimensions, respectively. Each cell in the matrix represents the IRG value at a certain location and time. Locations are distinguished by the time at which they were occupied by the focal individual. For example, $\operatorname{IRG}\left(l\left(t_{2}\right), t_{1}\right)$ indicates the IRG value at time $t_{1}$ at a location $l\left(t_{2}\right)$ that was occupied by the focal individual at time $t_{2}$. Each row is a time series of springness for a given location during the focal time period, in consecutive time periods $\left(t_{1}, t_{2}, \ldots t_{T}\right)$. Because we used functional-form NDVI and IRG time series, the temporal resolution is constrained only by GPS relocation frequency and not by the 16-day frequency of MODIS NDVI images. For most analyses, we chose a 1-day resolution for both dimensions of the space-time-time matrix in order to address the fact that many deer completed their migration in just a few days. We used coarser resolutions for graphical representation and when pattern detection was impeded by high noise levels in the IRG space-time-time matrix.

Matrix rows represent the relocation clusters associated with each day, in order of occupation from top to bottom. Therefore, a value on the matrix diagonal (top left to bottom right) gives the median IRG value experienced at a given relocation cluster on the day that it was actually occupied by the focal individual, and the diagonal itself is the time series of IRG values experienced in 1-day intervals throughout the focal period:

$$
\left(\begin{array}{c}
\operatorname{IRG}\left(l\left(t_{1}\right), t_{1}\right) \\
\operatorname{IRG}\left(l\left(t_{2}\right), t_{2}\right) \\
\vdots \\
\operatorname{IRG}\left(l\left(t_{T}\right), t_{T}\right)
\end{array}\right)
$$

Vectors extracted from the matrix that do not follow the diagonal represent IRG time series that would be experienced if the individual were to follow alternate spaceuse tactics within the constraints of the matrix. Note that each relocation cluster associated with a different time period represents a different row in the matrix, even if an individual uses the same physical locations in subsequent periods.

From each individual's IRG time matrix, we calculated the cumulative IRG (CIRG, cumulative springness) as the sum of IRG values associated with daily relocation clusters at the time they were occupied during the focal period (153 days total):

$$
\mathrm{CIRG}=\sum_{i}^{T} \operatorname{IRG}\left(l\left(t_{i}\right), t_{i}\right) .
$$

In addition to yielding the CIRG value associated with an individual's actual trajectory through the space-time-time matrix, this approach also permits calculation of cumulative springness associated with alternate trajectories. Out of all possible hypothetical trajectories through the spacetime-time matrix, we were interested mainly in the subset that gets at the question, What NDVI would a migratory individual have experienced if it had remained at its winter range instead of moving to the summer range? Therefore, in addition to calculating the CIRG experienced during the focal period, for migratory animals we also constructed an alternative resident trajectory of average IRG values of location clusters associated with the winter range during the time spent at the summer range and then substituted these during the calculation of CIRG.

To facilitate understanding of the structure of the spacetime-time matrix, one could think about it as a city's network of bus lines experienced from the perspective of a traveler. Each location's IRG time series is represented by a separate bus line. For simplicity, we assume that each line has the same number of equally timed stops. A traveler, in our case representing an individual red deer, uses several bus lines in order to reach the destination, but each line will follow its predetermined schedule and course of stops (represented by one row in the matrix), regardless of where and when the traveler decides to embark and disembark. The predetermined sequence of stops of a bus line is represented by the series of cells in a row of the matrix. The order of rows is determined by the order in which bus lines were used, and the travel itinerary-the chronological sequence of bus lines and stops driven through or switched at-is the diagonal through the matrix. Various alternative destinations and itineraries can be constructed from the network of bus lines, equivalent to the alternative trajectories through the space-time-time matrix.

\section{Do Migratory Red Deer Pursue the Green Wave?}

We were interested in three main comparisons in this part of the analysis: (1) the average date of peak IRG at the winter and summer ranges (P1), (2) plant phenology experienced by migratory and resident deer (P2), and (3) actual plant phenology experienced by migratory individuals, contrasted with plant phenology that could have been experienced by each individual if it had remained resident (P3). We used linear mixed-effects regression (function 
lmer in the nlme package in R, v. 2.13; R Development Core Team 2011) to make these comparisons and to test for and quantify the effect of covariates. We implemented most analyses separately for males and females, to account for differences in habitat use and responses to demographic factors that characterize highly polygynous ungulates such as red deer (Clutton-Brock et al. 1982).

P1. To test whether phenology was delayed at the summer range, we first calculated the difference between the median dates of peak IRG for relocations of each migratory individual at its summer and winter ranges. We used this measure of phenological delay at the summer range as the response variable and region as the only fixed effect, incorporated with the intention to quantify possible differences between our study regions. Individual ID and year were added as crossed random effects.

$P 2$. We tested whether migrants experienced more spring than resident deer by regressing CIRG on the spaceuse tactic (migratory vs. resident). The full model included the following additional independent variables: (1) a topographic-diversity index for relocations at the winter range, calculated on the basis of municipalities as a Shannon-Wiener diversity of altitudes 0-100, 100-200, 200300, 300-400, 400-500, 500-600, and 600-700 m (areas at exactly $0 \mathrm{~m}$ or $>700 \mathrm{~m}$ were excluded), and proportion of high-altitude habitat (segment 250-700 m), (2) deer density (number of harvested red deer per $\mathrm{km}^{2}$ of red deer habitat, as approved by management authorities [Mysterud et al. 2007], assessed on the scale of municipalities), and (3) proportion of GPS relocations in the winter range that were classified as landcover-type agriculture fields (based on the 1:50,000-scale AR50 habitat map created by the Norwegian Forest and Landscape Institute, http:// www.skogoglandskap.no). The most complex model also included two-way interactions between space-use tactic and all other independent variables. This analysis included all data from red deer monitoring seasons categorized as either migratory or resident.

P3. To test whether migrants experienced more spring than they would have had they remained resident, we regressed $\triangle$ CIRG (i.e., the difference between actual and hypothetical CIRG of migrants) on several covariates: (1) distance between summer and winter ranges, (2) difference in average elevation at the summer and winter ranges, and (3) topographic diversity at the summer range. In the models targeting P2 and P3, we included region and year as crossed random effects and individual ID nested within region. For all linear mixed-effects models used in this analysis, terms associated with fixed effects were retained in the final model through backward selection (Crawley 2007) if their effect on the response was statistically significant or suggested a trend $(P<.1)$. Where doing so facilitated comparisons between regression coefficients for males and females, we also retained terms that were statistically significant for one sex but not for the other. Goodness of fit for models was determined from inspection of plots of standardized residuals over fitted values and plots of response over fitted values (Crawley 2007).

\section{Do Red Deer Surf or Jump the Green Wave?}

The objectives of this part of the analysis were (1) to determine whether the speed of migration matched the speed with which phenology advanced from the winter range to the summer range (P4), (2) to identify whether migrants experienced plant phenology near the peak green-up during migration (P5), and (3) to determine whether there is indication of phenology tracking in the space-time-time matrix throughout the growing season, beyond the migration period (P6). We limited analyses P4 and P5 to migratory individuals for which the date of peak IRG was later at relocations in the summer range than that in the winter range $(P<.05)$. Both migratory and resident deer were included in analysis P6.

P4. To test whether the speed of migration matched the speed of the green wave, we first calculated both the overall speed with which peak IRG advanced over the distance between summer and winter ranges and the speed of migration. We then compiled this information into a new data set based on the original data, with two records for each spring migration event, one with the speed of migration and one with the speed of the green wave, and an additional categorical variable called "source" (green wave vs. migrant). The speed variable (log transformed) was used as the response in a linear regression, and region and source (together with their interaction) were used as fixed effects. Results from a preliminary mixed-effects regression model indicated that random effects of year and ID were negligible, and so we used a simple linear regression instead.

P5. To test whether some red deer experienced the top of the green wave for an extended period during migration, we utilized the median date of the maximum rate of greenup at a location occupied by individual red deer, regressed on the day on which that location was occupied. The strategy was to identify deer trajectories that, for any length, tracked the diagonal (i.e., where the date of maximum rate of green-up at a given location is the date on which that location was occupied), which we interpreted as surfing. The basic rationale of this analysis was that slopes similar to 1 represent surfing and a slope steeper than 1 represents jumping. Initial inspection of the data (plots of the day of peak IRG at a daily location vs. the day that location was occupied) revealed the common occurrence of abrupt changes in the slope. We therefore fitted segmented models, using the segmented function in R (Muggeo 2003), 
allowing up to three breaks (one to four segments) and then selected the best-performing model on the basis of the Akaike Information Criterion (Burnham and Anderson 2002).

P6. The previous analysis was targeted at the relatively short migration period, and therefore it was based on IRG and relocation data at a 1-day resolution. To explore whether red deer in our study tracked phenology during the wider growing season, not limited to the migration period, we left IRG time series at a 1-day resolution but pooled relocation data by 16 -day periods to reduce noise and facilitate pattern recognition. This resulted in spacetime-time matrices for each monitoring season with 10 rows and 153 columns for the focal period. For each monitoring season of migrant (201 seasons) and resident (93 seasons) deer, we then measured how many of the 10 IRG values on the diagonal were at least $60 \%$ of peak IRG (i.e., on average within 14 days of the diagonal), to quantify the extent of overall phenology tracking during the focal period. We used this measure to test for differences between migrants and resident deer in a generalized mixedeffects linear regression model (Poisson-distributed response) with study region as a random effect.

\section{Results}

\section{Red Deer Movements}

Of the 267 monitoring seasons of female red deer, 148 (55.4\%) exhibited patterns that were indicative of seasonal migration, 83 (31.1\%) were resident, and 36 (13.5\%) were classified as "other." Of 86 monitoring seasons of male deer, $53(61.6 \%)$ were migratory, 10 (11.6\%) were resident, and $23(26.7 \%)$ were categorized as "other." Of the 59 monitoring seasons of male and female deer that were categorized as neither migratory nor resident, nine were apparent cases of dispersal (fig. B6), 19 were incomplete (i.e., monitoring ended before return to the winter range or dispersal could be confirmed; fig. B5), and 31 were ambiguous or irregular (fig. B7). The median date of spring migration was May 9 (females: May 8; males: May 11; combined range: March 26-July 15), and migration had an average duration of 7.41 days $(S D=10.6$ days; females: 5.9 days; males: 11.6 days; combined range: $<1-$ 54 days) and was heavily skewed toward shorter migrations, with a median of 2.57 days (females: 2.31 days, males: 5.75 days). The average distance migrated was 23 $\mathrm{km}(\mathrm{SD}=17.42 \mathrm{~km}$; females: $21.6 \mathrm{~km}$; males: $26.9 \mathrm{~km}$; combined range: $3.1-84.9 \mathrm{~km}$ ). On average, migrants remained at the summer range for 121.5 days $(\mathrm{SD}=37.5$ days; females: 124.2 days; males: 113.9 days; combined range: 7-229 days). For the analytical tests of predictions P1-P6 detailed below, we included only data from deer classified as migratory and/or resident, which represented the bulk of the data.

\section{Do Migratory Red Deer Pursue the Green Wave?}

P1. Supporting P1, the average date of peak IRG (i.e., maximum spring), depending on region, occurred between 12 and 34 days later at the summer range than at winter ranges (females: 12-35 days; males: 11-82 days; regression results in table $\mathrm{B} 8$, available online). On an individual level, the date of peak green-up was later at the summer range than that at the winter range for 174 (86.6\%) females: $87.2 \%$, males: $84.9 \%$ ) of a total of 201 deer migrations (based on individual $t$-tests comparing summer and winter range relocations for each migration; $P<.05)$.

P2. Consistent with P2, female migrants experienced $33.2 \%$ and males $24.1 \%$ greater CIRG throughout the 153 day focal period (April 1-August 31) than resident individuals of the same sex. For females, space-use tactic and density remained as fixed effects in the final model, and for males, space-use tactic, topographic diversity at the winter range (or main range for residents), and their interaction were the fixed effects: increasing topographic diversity resulted in a gain in CIRG for migrants but not for residents. A trend of a density effect was present for males, comparable in magnitude to the density effect in females (table B9, available online). A previous study on the same population had shown that space-use tactics were highly consistent from year to year (Mysterud et al. 2011). In addition, in the model testing P2 the random effect of individual (ID) was important, at least for females (2 years of data for 47 individuals; likelihood ratio test: $\chi^{2}=$ 11.23, $P<.001)$.

P3. Consistent with P3, migrants experienced greater CIRG than they would have had they remained resident (fig. 4), resulting in both sexes mainly from a positive effect of the gain in elevation during migration (females: $\beta_{\text {meters }}=0.034, \mathrm{SE}=0.006, t=5.789, P<.001$; males: $\left.\beta_{\text {meters }}=0.031, \mathrm{SE}=0.007, t=4.294, P<.001\right)$. For females, distance between winter and summer ranges had an additional positive effect $\left(\beta_{\text {kilometers }}=0.163, \mathrm{SE}=\right.$ $0.059, t=2.74, P=.007)$, and there was a trend of a positive effect of topographic diversity at the summer range $(\beta=6.15, \mathrm{SE}=3.45, t=1.783, P=.077)$. For males, neither distance between the ranges $\left(\beta_{\text {kilometers }}=\right.$ $0.138, \mathrm{SE}=0.142, t=1.688, P=.098)$ nor topographic diversity at the summer range $(\beta=9.394, \mathrm{SE}=6.292$, $t=1.493, P=.142$ ) had a statistically significant effect on CIRG, but the coefficient estimates were comparable in magnitude to those in the female model. From predictions of models for testing P2 (total IRG experienced by migrants) and P3 (gain in IRG as a result of migration), 

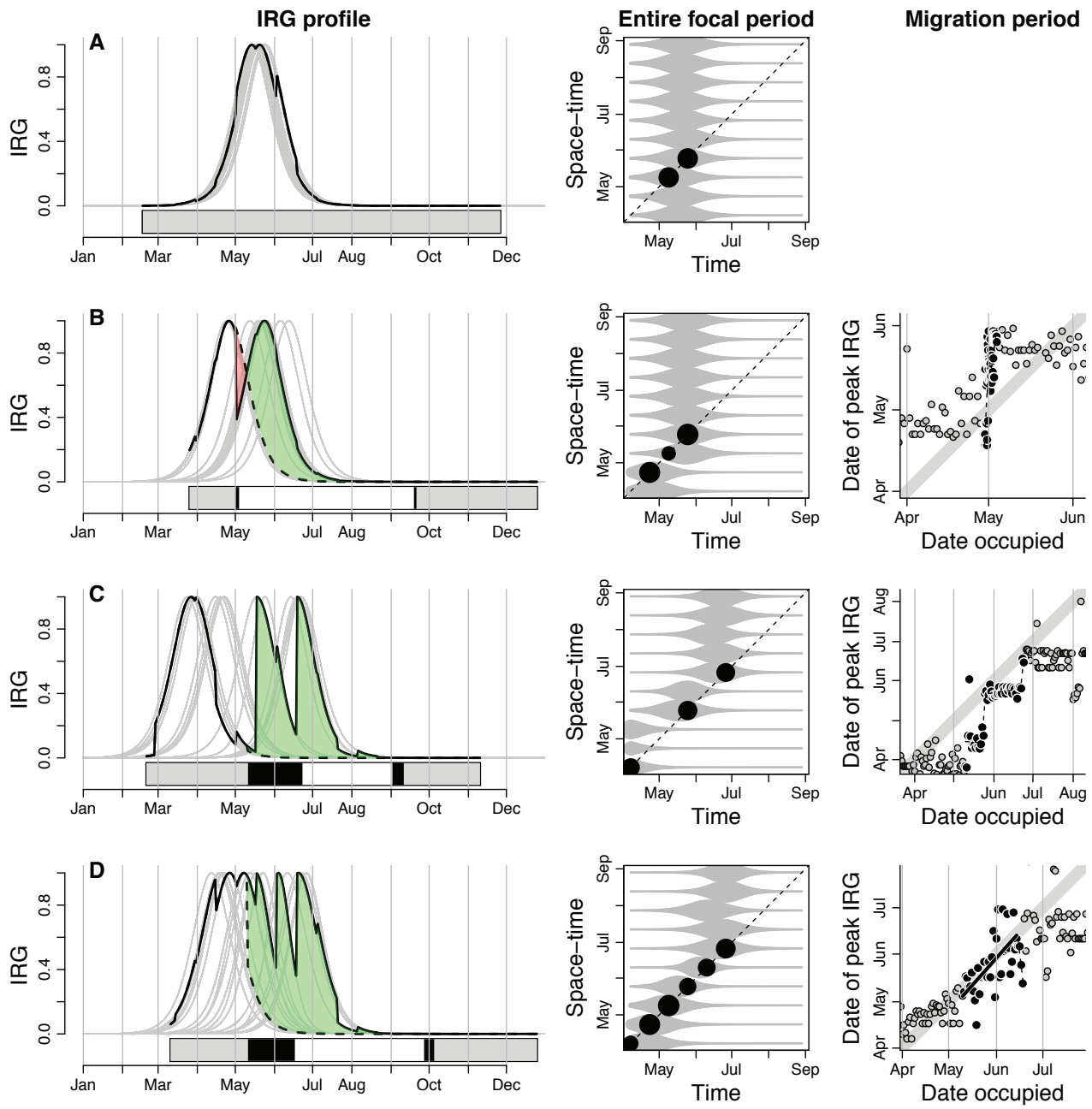

Figure 4: Patterns of springness (instantaneous rate of green-up [IRG]) experienced by one resident $(A)$ and three migratory Norwegian red deer $(B-D)$. $B$ shows the most common pattern among migratory red deer, namely, two peaks in IRG experienced, separated by an abrupt migration. Plots in the left column show the IRG profile through the course of the monitoring period. IRG time series associated with each relocation are shown as gray lines. The solid black line marks the IRG actually experienced by red deer throughout the monitoring period, and the dashed line marks the IRG pattern a deer would have experienced had it remained resident. Gains in cumulative IRG $(\triangle \mathrm{CIRG})$ as a consequence of migration are indicated by green areas and losses with red $(B)$. To reduce noise in the graphical representation, IRG time series from each 16-day period are pooled into a single line, whereas the calculation of cumulative IRG is based on 1-day resolution. The horizontal bar at the bottom of the frame indicates time spent at the winter range (gray), during migration (black), and at the summer range (white). Plots in the middle column are direct visual representations of the space-time-time matrix of IRG values. Time series of IRG values for a given 16-day location cluster are shown as horizontal gray lines, with the thicker section corresponding to the spring greenup. These time series are arranged along the $Y$-axis in order of occupation by the individual red deer (bottom to top). The diagonal represents IRG experienced at the time a location cluster was occupied, with black circles (size corresponding to current IRG) where the IRG value is within $60 \%$ of peak IRG. Plots in the right column show the relationship between the date of peak instantaneous green-up at a given location and the date at which that location was occupied during migration (open circles: winter range; black circles: spring 
we can calculate that both male and female migrants gained $43 \%$ in cumulative springness as a consequence of migration or, conversely, that migrants would have lost $30 \%$ in cumulative springness had they remained resident. Overall, $84.6 \%$ of all migrants experienced a longer or more intense spring as a result of migration.

Evaluating potential fitness effects, we regressed body weight at the time of marking (typically, January-March, with a sex-specific adjustment for measurement date to account for systematic weight changes throughout the season) on CIRG for the subset of red deer in our data set with weight measurements. We found a positive relationship between CIRG and body weight for male red deer $(N=26, \beta=0.587, \mathrm{SE}=0.266, t=2.201, P=.038)$, but not for females $(N=60, \beta=0.015, \mathrm{SE}=0.157$, $t=0.095, P=.925)$.

As suggested by Hebblewhite et al. (2008), resident individuals may adopt space-use tactics that allow them to partially compensate for the effects of not migrating. We found evidence that female migrants, had they forgone migration, would have done worse (in terms of CIRG) than resident animals $\left(\beta_{\text {resident }}=3.761, \mathrm{SE}=1.184, t=\right.$ $3.177, P=.002)$. Although the effect was not statistically significant in males $\left(\beta_{\text {resident }}=4.525, \mathrm{SE}=2.888, t=\right.$ $1.567, P=.122$ ), the magnitude of the estimate was similar to that in females. From the predictions of this model and the model for testing P2, we calculated an average $18.5 \%$ compensation by female residents, compared with the predicted loss in CIRG that migrants would incur if they remained at the winter range and did not change their relocation patterns.

In order to test whether animals were more likely to migrate in areas where migration led to greater gains in CIRG, we grouped our data by administrative unit. For this we chose the municipalities $(N=65)$ in which red deer were captured and marked, as study region $(N=7)$ was too coarse a category. The random effect of region proved to be negligible in an initial generalized mixedeffects model (logit link function); therefore, we used a logistic regression with only fixed effects for the analysis. We found that the proportion of migrants in an area increased as the average gain from migration (mean $\Delta$ CIRG for migratory deer in that region) increased $(\beta=0.126$, $\mathrm{SE}=0.037, \exp (\beta)=1.135, z=3.411, P<.001$; fig. 5$)$. Average distance between summer and winter ranges and average elevation gain during migration dropped out during model selection.

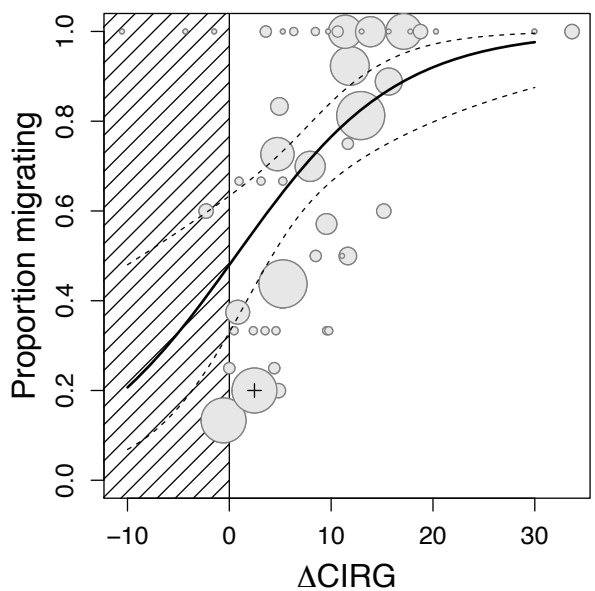

Figure 5: Proportion of red deer migrating in relation to the average gain in cumulative springness experienced as a result of migration. Individual data are grouped by the municipality in which deer were captured and marked, represented as circles. The relative size of the circles indicates the size of the sample associated with each municipality ( $N$ ranging from 2 to 16 ). Observations that fall within the hatched area represent municipalities where associated migrants, on average, experienced a loss in cumulative springness. Predictions from a logistic regression model are superimposed (with municipalities as the observation units), together with $95 \%$ confidence interval boundaries. Ten municipalities with no migrants (only 1 or 2 individuals in each) and five municipalities with only one migratory individual and no residents were pooled in the analysis (data point marked with a plus sign), to avoid bias in the model estimates that would result if municipalities with no migrants (and therefore no estimate of gain in cumulative springness) were excluded.

\section{Do Red Deer Surf or Jump the Green Wave?}

P4. Instead of the tight match between the speed of migration and the speed of the green wave that we would expect if migrants closely tracked phenological development, migration happened very fast, advancing between 4.4 and $15.3 \mathrm{~km} /$ day, whereas the speed of green-up between relocations at summer and winter ranges was between 0.5 and $2.2 \mathrm{~km} /$ day, depending on the study region (fig. 6). This is also reflected by the common occurrence of a two-humped pattern in the IRG time series of mi-

migration period; gray circles: summer range). The diagonal (thick gray line) represents the leading edge of the green wave, and data points on the line are indicative of locations occupied at the time of their peak rate of green-up. The patterns shown for $B-D$ are indicative of jumping, jumping with stopover, and surfing, respectively. Regression lines are dashed, with the surfing segment shown in bold ( $D$ ). 


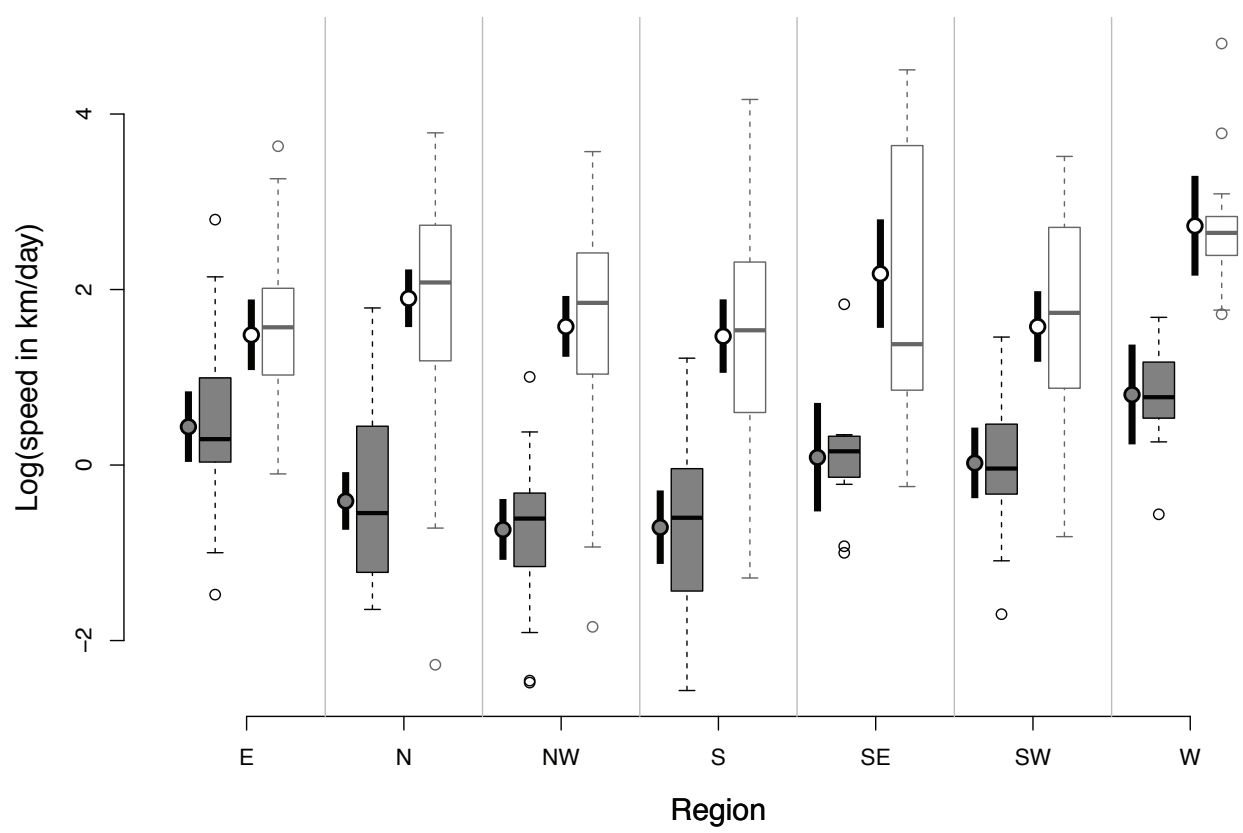

Figure 6: Box-and-whisker plots comparing the distribution of (log-transformed) speed of migration of red deer (white boxes) and the speed with which spring advances (gray boxes) between winter and summer ranges in seven different study regions in Norway. White (migration) and gray circles (green wave) to the left of each box plot show the mean speed predicted by a linear regression model, and vertical bars indicate the $95 \%$ confidence interval for each prediction.

grants, where individuals caught the first phenological spring at the winter range and-after a slump in IRG-a second, delayed spring at the summer range (fig. $4 B$; see also fig. 1C). Of the 174 migrations with delayed spring at the summer range, $5.8 \%$ departed from the winter range more than 14 days before it had reached its average maximum green-up rate, and $13.2 \%$ arrived at the summer range more than 14 days after the average date of maximum green-up rate (i.e., spring) at that range had passed.

P5. Rather than tracking the peak in IRG during migration, we found that most (78\%) of the 174 migration events with delayed spring at the summer ranges were characterized by a rapid jump with respect to the green wave (fig. $4 B$ ). Our criteria identified nine instances $(5.2 \%$; five male and four female) of surfing the green wave during migration (figs. $4 D, \mathrm{~B} 10$, the latter available online). The remaining 29 (16.7\%) migrations did not fall in either the surfing or jumping category and included migrations without a clear trajectory in the regression, migrations that were too far removed from the diagonal ( $>14$ days), or slopes that were slower than that required to be classified as surfing. The approach is likely to have missed additional instances of jumping, because the quicker migration is, the fewer data points are available for detecting slope differences in the regression model. Six of the nine migrations classified as surfing and 25 of the 135 migrations classified as jumping contained multiday stopovers ( $\geq 5$ days). A logistic regression model indicated that red deer were more likely to surf the green wave during migration if they were male $\left(\beta_{\text {male }}=1.466, \mathrm{SE}=0.736, \exp (\beta)=4.33, z=\right.$ 1.992, $P=.046)$ or with increasing delay in the date of peak IRG at the summer range compared with the winter range $\left(\beta_{\mathrm{days}}=0.053, \mathrm{SE}=0.018, \exp (\beta)=1.054, z=\right.$ 2.845, $P=.004)$.

P6. Although the vast majority of red deer were jumping the green wave during migration, a substantial proportion of both males $(49.1 \%)$ and females (43.9\%) showed an overall pattern of phenology tracking during the growing season. This was manifested in our analysis as three or more (up to six) 16-day relocation clusters that were occupied when their average IRG value was within $60 \%$ of peak IRG (fig. 4 , middle). Ten percent of resident 
males and $9.6 \%$ of resident females also tracked phenology for three or more (up to four) relocation clusters on the space-time-time matrix diagonal, but phenology tracking was more pronounced in migrants than in residents, at least for females (females: $\beta_{\text {migrant }}=0.448, \mathrm{SE}=0.107$, $z=4.194, \quad P=.001 ;$ males: $\beta_{\text {migrant }}=0.294, \quad \mathrm{SE}=$ $0.252, z=1.168, P=.243)$.

\section{Discussion}

Despite a diverse set of red deer space-use tactics, the patterns that emerged from this study are clear. Migratory red deer pursue the green wave, enjoying a substantial gain (females: $33 \%$, males: $24 \%$ ) in access to early plant phenology compared with resident deer. However, the majority of migrants moved between often distant winter and summer ranges in one or a few abrupt moves and used little time en route (fig. $4 B$ ), thus not exploiting the full potential of the green wave. Many red deer did surf on a wave of plant green-up over the wider time frame of the growing season (beyond the migration period), mostly through smaller shifts in areas used at the main ranges (summer and winter). In this way, phenology can also be tracked by resident deer without establishing distinct seasonal ranges, but green-wave surfing was much more pronounced in migrants. The latter apparently used migration to escape the confines of their winter range and set themselves up with better or continued options to track early plant phenology at the summer range. In some species, such as migratory geese, migration is used not only to commute between seasonal ranges but also to acquire resources en route that are needed for breeding and other activities at the summer range (e.g., van Wijk et al. 2012). For most Norwegian red deer, on the other hand, migration between seasonal ranges is apparently a means to an end rather than a way to access resources along the way.

\section{What Are the Constraints That Promote Jumping over Surfing the Green Wave?}

Although red deer were able to surf the green wave without closely tracking early plant development during migration, exploiting the full potential of the phenological gradient between winter and summer ranges would have led to even greater gains in springness. Remaining on the leading edge of the green wave for as continuously and as long as possible would maximize the benefits of migration in terms of access to high-quality forage (fig. $1 A$ ), and we would expect surfers to be rewarded with fitness benefits derived from better body condition. In some cases, there are obvious limits to how closely migrants can track phenology during migration. Geographic discontinuity of resources (forage, shelter, etc.) along possible migration routes can dictate a pattern of one or more quick migration events, possibly interrupted by stopovers. This is the case for migratory waterfowl using coastal sites, wetlands, or agricultural fields as stopovers during migration (Owen 1980; van der Graaf et al. 2006; Bauer et al. 2008), as well as for terrestrial birds (Kuenzi et al. 1991), bats (Cryan and Brown 2007), and insects (Feng et al. 2009) that rest on islands during transocean migrations. Although discontinuity in suitable habitat along the migration route may prevent surfing, we can probably exclude this as a general explanation for the prevalence of jumping among Norwegian red deer, because we found that habitat suitability (determined to a large extent by forest cover; Loe et al. 2012) along the migration route was intermediate between that at the winter and summer ranges (fig. B11, available online). Why, then, is there a marked mismatch between plant phenological development along the migration route and the speed of migration of the typical Norwegian red deer?

Even in cases where resource access is not limited along the migration route and the green wave rolls across the landscape uninterrupted, constraints and trade-offs could prompt migrants to jump rather than surf the wave of phenological development. Many prey species and their offspring are particularly vulnerable to predation during migration, presumably providing an incentive for faster migratory movements in an effort to reduce exposure to risk (Festa-Bianchet 1988; Hebblewhite and Merrill 2007, 2009). Also, the timing of seasonal migration may coincide with or even be partially motivated by life-history aspects beyond herbivory, such as calving, which may determine the timing or constrain the duration of migration. For example, migratory Norwegian red deer typically give birth shortly after arriving at their summer range (Loe et al. 2005), and females may want to reach their destination before a newborn calf restricts movements.

Migrants may benefit from cutting migration short and arriving early at their destination if they are competing with conspecifics for access to the best foraging areas, shelter, or mates. This appears to be a common trade-off in birds (Kokko et al. 2006), and it has also been suggested that roe deer (Capreolus capreolus) males, which are territorial during summer, may advance spring migration relative to females to become established before the arrival of competitors (Mysterud 1999). Whether animals without marked territoriality can gain a competitive advantage from speeding up migration is less clear. Established home ranges of conspecifics at and between seasonal ranges may also limit the time migrants can spend en route. Mysterud et al. (2011) suggested that the apparent negative density dependence of the proportion of migrants among Norwegian red deer may be linked to the social-fence hypothesis, which has been offered as an explanation for 
population regulation and density-dependent dispersal in microtine rodents and birds (Hestbeck 1982; Matthysen 2005).

In their review of research on ungulate migration, Bolger et al. (2008) make a distinction between a process that consists of many decisions based on local information from the immediate surroundings and one with fewer large-scale decisions that require experience, memory, and/ or a genetic basis. Our findings seem to suggest the latter, namely, decisions that involve some kind of expectation or knowledge-perhaps culturally transmitted (Sweanor and Sandegren 1988; Albon and Langvatn 1992; Nelson 1998)_about the conditions at the summer range before migration is undertaken. According to Dingle (1996), the lack of a response to proximate cues of forage during the migration phase is an important aspect of true migration, as opposed to foraging movements, where animals are expected to respond to immediate signs of forage availability. Even if red deer utilize environmental cues in their vicinity to assess where they are on the green wave, they may have access only to imperfect information about their position in relation to the spatiotemporal arrangement of resources. This, in turn, could lead to migrations that are out of sync with the green wave. When the green wave progresses relatively quickly (i.e., when the difference in the dates of peak green-up at the summer and winter ranges is small), the benefits derived from surfing the green wave may be outweighed by the cost of gathering accurate information, prompting migrants to jump rather than surf.

\section{Migration and Home Range Familiarity}

The above trade-offs and limitations, coupled with inherent benefits of established home ranges-for example, familiarity with the spatiotemporal distribution of resources and risk (Greenwood and Harvey 1982; Stamps 1995; McDougall and Kramer 2007)_may constrain a migrant's ability or willingness to freely track plant phenology during long-distance migration. Specifically, the desire to remain in well-used and thus familiar areas, such as two distinct seasonal ranges, could interfere with timely access to patches with intermediate peaks in green-up between the extremes. Surfing, whether it is accomplished through a series of stopovers or through slow roaming movements, means spending more time on the migration route. By definition, the more distinct and heavily used seasonal home ranges are, the less time is available to spend migrating between them. The ultimate and proximate causes for the formation of home ranges are the topic of research (Borger et al. 2008; Van Moorter et al. 2009) that has yet to be integrated with the FMH. Future investigations into potential trade-offs between optimal pursuit of the green wave and concentration of activity in well-used and thus familiar home ranges may help further explain migration patterns.

$$
\text { Stopovers and Phenology Tracking }
$$

Stopover sites on the migration route could provide a way to balance the need for establishing home ranges, albeit temporary ones, with some reasonable match between a migrant's movements and the green wave. Appropriately timed stopovers can give access to higher-quality forage or greater biomass during migration, which is the pattern we observed for six of the nine migrations identified as surfing in this study and for several other migratory individuals where successive jumps were separated by stopovers (fig. 4C). However, because of the abruptness of most migrations, only $18 \%$ of migrations in our study included multiday stopovers ( $\geq 5$ days), whereas stopovers seem to be a prominent feature in other systems. For example, Sawyer and Kauffman (2011) found that migratory mule deer (Odocoileus hemionus) in Wyoming took, on average, 3 weeks to complete a track that could be covered in a few days and spent $95 \%$ of that time at a series of stopover sites, thereby tracking phenology. Similarly, van Wijk et al. (2012) showed that white-fronted geese (Anser albifrons albifrons) used a series of stopovers corresponding to the peaks in temperature acceleration and thus tracked the front of the green wave during spring migration.

\section{Migrants versus Residents}

The delay of the arrival of spring at the summer ranges, the resulting gain in springness experienced by migrants, and clear patterns of tracking early plant phenology over an extended time period point toward a central role of differential forage maturation in driving seasonal migration in ungulates. Our findings add to a growing list of evidence in support of the FMH for mammals (Albon and Langvatn 1992; Pettorelli et al. 2005a; Richter and Cumming 2006; Hebblewhite et al. 2008; Wang et al. 2010; Sawyer and Kauffman 2011), birds (van der Graaf et al. 2006; van Wijk et al. 2012), and fish (Walli et al. 2009). By definition, red deer that tracked phenology during the growing season to a greater extent enjoyed a higher CIRG, because they spent more time near the top of green wave. We found a positive relationship between CIRG and the marking weight for male red deer but not for females. The lack of an effect in females could be explained by the constraints imposed by calves at heel (Bonenfant et al. 2004) or if females allocate surplus energy to reproduction (Bronson 1989). We also found indirect support for a possible fitness effect: the proportion of migratory deer in an area increases as the average benefit of migrating (in terms of a gain in springness) grows (fig. 5). Although resident 
red deer in our study experienced reduced springness during the growing season, compared with migrants, we found that they were still better off than migrants would have been had they stayed at the winter range. One possible explanation is that residents adopt space-use tactics that allow them to buffer the effects of not migrating, for example, by exploring sufficient variation in the timing of green-up within their annual range. Similarly, studies in elk and moose (Alces alces) have shown that resident individuals exhibit greater forage selectivity at finer scales (Histøl and Hjeljord 1993; Hebblewhite et al. 2008). There is a clear need for further studies that assess the relative fitness of residents and migratory animals to understand why both tactics so commonly persist alongside each other.

\section{Using the NDVI to Link Herbivore Movements with Plant Phenology}

Our study was possible because of the availability of remote-sensing data on plant phenology (i.e., MODIS NDVI), but the focus on a single measure of forage quality is also one of its weaknesses. The satellite-derived NDVI measures the phenological state (greenness) of the plant community, not specifically that of plants utilized by red deer, and it does so at a relatively coarse spatial scale (250 $\mathrm{m} \times 250 \mathrm{~m})$, given that the scale of forage selection in red deer ranges from the level of plants to the landscape level. Small-scale adjustments in forage locations and shifts between main forage species are missed by the satellite, but these may enable red deer to access early-phenology vegetation at sites that are seemingly past their peak greenup. Given the fairly large variation in phenology among sites and an established link between the NDVI and ungulate forage quality (Hebblewhite et al. 2008; Hamel et al. 2009), we find it unlikely that such limitations interfere with the interpretation of the main patterns observed in this study. Furthermore, NDVI data apparently measured habitat use at a scale small enough to enable us to detect that both migratory and resident deer made adjustments in their exposure to early plant phenology. Despite limited consideration in this study for other important determinants of habitat suitability (topography, habitat structure, plant community, etc.), the patterns that we detected were pronounced, suggesting that the NDVI was indeed an appropriate measure of spatiotemporal changes in phenology experienced by red deer.

\section{Migration Tactics and Conservation}

A number of threats resulting from anthropogenic changes to the environment converge on migratory species and migration as an ecological phenomenon (Berger 2004; Berger et al. 2008; Harris et al. 2009). Habitat destruction/ fragmentation by artificial barriers such as railroads (Ito et al. 2005, 2008) and agricultural development (Voeten et al. 2010) may impede movement between seasonal ranges, and climate change may eliminate the incentive for migration altogether by affecting the spatiotemporal configuration of resources (Sharma et al. 2009). Understanding the drivers and constraints of migration is therefore critical for conservation and management. The way migrants use corridors between seasonal ranges is bound to have especially important consequences for the persistence of migratory populations and migration itself (Sawyer et al. 2009). Migrants that move quickly between seasonal ranges, spending little time en route and utilizing few resources, are likely less specific in their habitat requirements and are less vulnerable (e.g., predation, hunting, exposure/starvation) during migration. Furthermore, each year some migratory ungulates and birds inflict agricultural and other costs (Ball and Dahlgren 2002; Skonhoft 2005; Nilsen et al. 2009), which invite anthropogenic manipulations of their populations and migrations (Wallin and Milberg 1995; Jefferies et al. 2004; Jonker et al. 2010). Migrants moving quickly between seasonal ranges have less opportunity to cause agricultural damage and thereby conflicts. This is particularly important, because ungulate conservation and management is often tightly linked with the management and mitigation of costs/damages (Reimoser and Putman 2011). In addition, migration patterns can affect the management of ungulate hunting seasons and possibly vice versa (Rudd et al. 1983; Holdo et al. 2010; Alisauskas et al. 2011).

The conservation of migration corridors, buffer zones, and stopover sites is now receiving substantial attention (Thirgood et al. 2004; Sawyer et al. 2009). Whether stopovers are used simply as resting sites during migration or as a way to better match migration with a spatiotemporal gradient in resources (such as fresh growth), they seem to be characteristic and possibly essential features of many migratory systems. Fragmentation of corridors and the loss of stopover sites could force migratory animals to use fewer stops along their migration route, thereby affecting their ability to match movement with resource state and perhaps, in some cases, preventing migration altogether.

\section{Conclusions}

By investigating how individual red deer experience the green wave, we gained insights into the ways migrants track a rolling wave of vegetation green-up across the landscape. We confirmed that space-use tactics have substantial consequences for an individual's access to an essential, spatiotemporally varying resource: phenological spring. Migration is a complex phenomenon; its whys and hows will continue to challenge ecologists and wildlife managers. 
Ungulate migration could be a manifestation of evolved behavior (Boone et al. 2006), cultural transmission (Albon and Langvatn 1992), real-time energy maximization (Holdo et al. 2009), or a combination of thereof. The makeup of these ultimate drivers of migration determines the ability of migratory populations to adapt to anthropogenic changes to the spatiotemporal arrangement of resources. Tightly linked with the drivers of migration are the cues migrants may use to decide when, where, and how to migrate. There is a need for research targeted at migration cues if we want to better understand how migratory herbivores respond to the nature of the green wave.

\section{Acknowledgments}

We thank A. Nielsen for initial advice on obtaining and processing the satellite-derived NDVI and A. Ordiz, V. Vazquez, and two anonymous reviewers for review and comments that lead to substantial improvements in the manuscript. This work would not have been possible without the MODIS NDVI data made available by NASA. The study was funded in part by the Research Council of Norway (NFR)-Natur og næring program (AREAL-project 179370) and the Norwegian Directorate for Nature Management. Red deer marking was mainly funded by game funds of various Norwegian counties, municipalities, and red deer management units. We are grateful to the people who have assisted in the marking of animals. R.B. was partially funded by grant 204202/F20 from the NFR. B.V.M. was funded by the Marie Curie Intra-European fellowship.

\section{Literature Cited}

Albon, S. D., and R. Langvatn. 1992. Plant phenology and the benefits of migration in a temperate ungulate. Oikos 65:502-513.

Alisauskas, R. T., R. F. Rockwell, K. W. Dufour, E. G. Cooch, G. Zimmerman, K. L. Drake, J. O. Leafloor, T. J. Moser, and E. T. Reed. 2011. Harvest, survival, and abundance of midcontinent lesser snow geese relative to population reduction efforts. Wildlife Monographs 179:1-42.

Ball, J. P., and J. Dahlgren. 2002. Browsing damage on pine (Pinus sylvestris and $P$. contorta) by a migrating moose (Alces alces) population in winter: relation to habit at composition and road barriers. Scandinavian Journal of Forest Research 17:427-435.

Bauer, S., M. Van Dinther, K.-A. Høgda, M. Klaassen, and J. Madsen. 2008. The consequences of climate-driven stop-over sites changes on migration schedules and fitness of Arctic geese. Journal of Animal Ecology 77:654-660.

Beck, P. S. A., C. Atzberger, K.-A. Høgda, B. Johansen, and A. K. Skidmore. 2006. Improved monitoring of vegetation dynamics at very high latitudes: a new method using MODIS NDVI. Remote Sensing of Environment 100:321-334.

Beck, P. S. A., T. J. Wang, A. K. Skidmore, and X. H. Liu. 2008. Displaying remotely sensed vegetation dynamics along natural gra- dients for ecological studies. International Journal of Remote Sensing 29:4277-4283.

Berger, J. 2004. The last mile: how to sustain long-distance migration in mammals. Conservation Biology 18:320-331.

Berger, J., J. K. Young, and K. M. Berger. 2008. Protecting migration corridors: challenges and optimism for Mongolian saiga. PLoS Biology 6:e165.

Bolger, D. T., W. D. Newmark, T. A. Morrison, and D. F. Doak. 2008. The need for integrative approaches to understand and conserve migratory ungulates. Ecology Letters 11:63-77.

Bonenfant, C., L. E. Loe, A. Mysterud, R. Langvatn, N. C. Stenseth, J.-M. Gaillard, and F. Klein. 2004. Multiple causes of sexual segregation in European red deer: enlightenments from varying breeding phenology at high and low latitude. Proceedings of the Royal Society B: Biological Sciences 271:883-892.

Boone, R. B., S. J. Thirgood, and J. G. C. Hopcraft. 2006. Serengeti wildebeest migratory patterns modeled from rainfall and new vegetation growth. Ecology 87:1987-1994.

Borger, L., B. D. Dalziel, and J. M. Fryxell. 2008. Are there general mechanisms of animal home range behaviour? a review and prospects for future research. Ecology Letters 11:637-650.

Brazda, A. R. 1953. Elk migration patterns, and some of the factors affecting movements in the Gallatin River drainage, Montana. Journal of Wildlife Management 17:9-23.

Bronson, F. H. 1989. Mammalian reproductive biology. University of Chicago Press, Chicago.

Bunnefeld, N., L. Borger, B. Van Moorter, C. M. Rolandsen, H. Dettki, E. J. Solberg, and G. Ericsson. 2011. A model-driven approach to quantify migration patterns: individual, regional and yearly differences. Journal of Animal Ecology 80:466-476.

Burnham, K. P., and D. R. Anderson. 2002. Model selection and multimodel inference: a practical information-theoretic approach. Springer, New York.

Choquenot, D. 1991. Density-dependent growth, body condition, and demography in feral donkeys: testing the food hypothesis. Ecology 72:805-813.

Clutton-Brock, T. H., F. E. Guinness, and S. D. Albon. 1982. Red deer: behavior and ecology of two sexes. University of Chicago Press, Chicago.

Crawley, M. J. 2007. The R book. Wiley, Chichester.

Cryan, P. M., and A. C. Brown. 2007. Migration of bats past a remote island offers clues toward the problem of bat fatalities at wind turbines. Biological Conservation 139:1-11.

Dingle, H. 1996. Migration: the biology of life on the move. Oxford University Press, New York.

Drent, R. H., B. S. Ebbinge, and B. Weijand. 1978. Balancing the energy budgets of Arctic-breeding geese throughout the annual cycle: a progress report. Verhandlungen der Ornithologischen $\mathrm{Ge}$ sellschaft in Bayern 23:239-264.

Feng, H. Q., X. F. Wu, B. Wu, and K. M. Wu. 2009. Seasonal migration of Helicoverpa armigera (Lepidoptera: Noctuidae) over the Bohai Sea. Journal of Economic Entomology 102:95-104.

Festa-Bianchet, M. 1988. Seasonal range selection in bighorn sheep: conflicts between forage quality, forage quantity, and predator avoidance. Oecologia (Berlin) 75:580-586.

Fryxell, J. M., J. Greever, and A. R. E. Sinclair. 1988. Why are migratory ungulates so abundant? American Naturalist 131:781-798.

Gaillard, J.-M., M. Festa-Bianchet, N. G. Yoccoz, A. Loison, and C. Toigo. 2000. Temporal variation in fitness components and pop- 
ulation dynamics of large herbivores. Annual Review of Ecology, Evolution, and Systematics 31:367-393.

Greenwood, P. J., and P. H. Harvey. 1982. The natal and breeding dispersal of birds. Annual Review of Ecology and Systematics 13: $1-21$.

Hamel, S., M. Garel, M. Festa-Bianchet, J.-M. Gaillard, and S. D. Côté. 2009. Spring normalized difference vegetation index (NDVI) predicts annual variation in timing of peak faecal crude protein in mountain ungulates. Journal of Applied Ecology 46:582-589.

Harris, G., S. Thirgood, J. G. C. Hopcraft, J. P. G. M. Cromsigt, and J. Berger. 2009. Global decline in aggregated migrations of large terrestrial mammals. Endangered Species Research 7:55-76.

Hebblewhite, M., and E. H. Merrill. 2007. Multiscale wolf predation risk for elk: does migration reduce risk? Oecologia (Berlin) 152: $377-387$.

- 2009. Trade-offs between predation risk and forage differ between migrant strategies in a migratory ungulate. Ecology 90: 3445-3454.

Hebblewhite, M., E. Merrill, and G. McDermid. 2008. A multi-scale test of the forage maturation hypothesis in a partially migratory ungulate population. Ecological Monographs 78:141-166.

Hestbeck, J. B. 1982. Population regulation of cyclic mammals: the social fence hypothesis. Oikos 39:157-163.

Hird, J. N., and G. J. McDermid. 2009. Noise reduction of NDVI time series: an empirical comparison of selected techniques. Remote Sensing of Environment 113:248-258.

Histøl, T., and O. Hjeljord. 1993. Winter feeding strategies of migrating and nonmigrating moose. Canadian Journal of Zoology 71:1421-1428.

Holdo, R. M., K. A. Galvin, E. Knapp, S. Polasky, R. Hilborn, and R. D. Holt. 2010. Responses to alternative rainfall regimes and antipoaching in a migratory system. Ecological Applications 20: 381-397.

Holdo, R. M., R. D. Holt, and J. M. Fryxell. 2009. Opposing rainfall and plant nutritional gradients best explain the wildebeest migration in the Serengeti. American Naturalist 173:431-445.

Ito, T. Y., N. Miura, B. Lhagvasuren, D. Enkhbileg, S. Takatsuki, A. Tsunekawa, and Z. W. Jiang. 2005. Preliminary evidence of a barrier effect of a railroad on the migration of Mongolian gazelles. Conservation Biology 19:945-948.

Ito, T. Y., A. Okada, B. Buuveibaatar, B. Lhagvasuren, S. Takatsuki, and A. Tsunekawa. 2008. One-sided barrier impact of an international railroad on Mongolian gazelles. Journal of Wildlife Management 72:940-943.

Jefferies, R. L., R. F. Rockwell, and K. E. Abraham. 2004. Agricultural food subsidies, migratory connectivity and large-scale disturbance in Arctic coastal systems: a case study. Integrative and Comparative Biology 44:130-139.

Jonker, R. M., G. Eichhorn, F. van Langevelde, and S. Bauer. 2010. Predation danger can explain changes in timing of migration: the case of the barnacle goose. PLoS ONE 5:e11369.

Karlsen, S. R., A. Elvebakk, K. A. Høgda, and B. Johansen. 2006. Satellite-based mapping of the growing season and bioclimatic zones in Fennoscandia. Global Ecology and Biogeography 15:416-430.

Karlsen, S. R., A. Tolvanen, E. Kubin, J. Poikolainen, K. A. Høgda, B. Johansen, F. S. Danks, P. Aspholm, F. E. Wielgolaski, and O. Makarova. 2008. MODIS-NDVI-based mapping of the length of the growing season in northern Fennoscandia. International Journal of Applied Earth Observation and Geoinformation 10:253-266.

Kokko, H., T. G. Gunnarsson, L. J. Morrell, and J. A. Gill. 2006. Why do female migratory birds arrive later than males? Journal of Animal Ecology 75:1293-1303.

Kuenzi, A. J., F. R. Moore, and T. R. Simons. 1991. Stopover of Neotropical landbird migrants on East Ship Island following transGulf migration. Condor 93:869-883.

Loe, L. E., C. Bonenfant, E. L. Meisingset, and A. Mysterud. 2012. Effects of spatial scale and sample size in GPS-based species distribution models: are the best models trivial for red deer management? European Journal of Wildlife Research 58:95-203.

Loe, L. E., C. Bonenfant, A. Mysterud, J.-M. Gaillard, R. Langvatn, F. Klein, C. Calenge, T. Ergon, N. Pettorelli, and N. C. Stenseth. 2005. Climate predictability and breeding phenology in red deer: timing and synchrony of rutting and calving in Norway and France. Journal of Animal Ecology 74:579-588.

Lundberg, P. 1988. The evolution of partial migration in birds. Trends in Ecology \& Evolution 3:172-175.

Matthysen, E. 2005. Density-dependent dispersal in birds and mammals. Ecography 28:403-416.

McDougall, P. T., and D. L. Kramer. 2007. Short-term behavioral consequences of territory relocation in a Caribbean damselfish, Stegastes diencaeus. Behavioral Ecology 18:53-61.

Meitner, C. J., L. P. Brower, and A. K. Davis. 2004. Migration patterns and environmental effects on stopover of monarch butterflies (Lepidoptera, Nymphalidae) at Peninsula Point, Michigan. Environmental Entomology 33:249-256.

Moore, F., and P. Kerlinger. 1987. Stopover and fat deposition by North-American wood-warblers (Parulinae) following spring migration over the Gulf of Mexico. Oecologia (Berlin) 74:47-54.

Muggeo, M. R. 2003. Estimating regression models with unknown break-points. Statistics in Medicine 22:3055-3071.

Mysterud, A. 1999. Seasonal migration pattern and home range of roe deer (Capreolus capreolus) in an altitudinal gradient in southern Norway. Journal of Zoology (London) 247:479-486.

Mysterud, A., L. E. Loe, B. Zimmermann, R. Bischof, V. Veiberg, and E. Meisingset. 2011. Partial migration in expanding red deer populations at northern latitudes: a role for density dependence? Oikos 120:1817-1825.

Mysterud, A., E. L. Meisingset, V. Veiberg, R. Langvatn, E. J. Solberg, L. E. Loe, and N. C. Stenseth. 2007. Monitoring population size of red deer Cervus elaphus: an evaluation of two types of census data from Norway. Wildlife Biology 13:285-298.

Nelson, M. E. 1998. Development of migratory behavior in northern white-tailed deer. Canadian Journal of Zoology 76:426-432.

Nielson, R. M., H. Sawyer, and T. L. McDonald. 2011. BBMM: Brownian bridge movement model. $\mathrm{R}$ package, version 2.2 . http://CRAN.R-project.org/package = BBMM.

Nilsen, E. B., A. Skonhoft, A. Mysterud, J. M. Milner, E. J. Solberg, H. P. Andreassen, and N. C. Stenseth. 2009. The role of ecological and economic factors in the management of a spatially structured moose Alces alces population. Wildlife Biology 15:10-23.

Owen, M. 1980. Wild geese of the world: their life history and ecology. Batsford, London.

Pettorelli, N., A. Mysterud, N. G. Yoccoz, R. Langvatn, and N. C. Stenseth. 2005a. Importance of climatological downscaling and plant phenology for red deer in heterogeneous landscapes. Proceedings of the Royal Society B: Biological Sciences 272:2357-2364.

Pettorelli, N., J. O. Vik, A. Mysterud, J.-M. Gaillard, C. J. Tucker, and N. C. Stenseth. 2005b. Using the satellite-derived NDVI to assess ecological responses to environmental change. Trends in Ecology \& Evolution 20:503-510. 
R Development Core Team. 2011. R: a language and environment for statistical computing. R Foundation for Statistical Computing, Vienna. http://www.R-project.org.

Reimoser, F., and R. Putman. 2011. Impacts of wild ungulates on vegetation: costs and benefits. Pages 144-191 in R. Putman, M. Apollonio, and R. Andersen, eds. Ungulate management in Europe: problems and practices. Cambridge University Press, Cambridge.

Richter, H. V., and G. S. Cumming. 2006. Food availability and annual migration of the straw-colored fruit bat (Eidolon helvum). Journal of Zoology (London) 268:35-44.

Rudd, W. J., A. L. Ward, and L. L. Irwin. 1983. Do split hunting seasons influence elk migrations for Yellowstone National Park? Wildlife Society Bulletin 11:328-331.

Sawyer, H., and M. J. Kauffman. 2011. Stopover ecology of a migratory ungulate. Journal of Animal Ecology 80:1078-1087.

Sawyer, H., M. J. Kauffman, R. M. Nielson, and J. S. Horne. 2009. Identifying and prioritizing ungulate migration routes for landscape-level conservation. Ecological Applications 19:2016-2025.

Sharma, S., S. Couturier, and S. D. Côté. 2009. Impacts of climate change on the seasonal distribution of migratory caribou. Global Change Biology 15:2549-2562.

Skonhoft, A. 2005. The costs and benefits of a migratory species under different management schemes. Journal of Environmental Management 76:167-175.

Stamps, J. 1995. Motor learning and the value of familiar space. American Naturalist 146:41-58.

Sweanor, P. Y., and F. Sandegren. 1988. Migratory behavior of related moose. Holarctic Ecology 11:190-193.

Thirgood, S., A. Mosser, S. Tham, G. Hopcraft, E. Mwangomo, T. Mlengeya, M. Kilewo, J. Fryxell, A. R. E. Sinclair, and M. Borner. 2004. Can parks protect migratory ungulates? the case of the Serengeti wildebeest. Animal Conservation 7:113-120.

Turchin, P. 1998. Quantitative analysis of movement: measuring and modeling population redistribution in animals and plants. Sinauer, Sunderland, MA.

van der Graaf, S. A. J., J. Stahl, A. Klimkowska, J. P. Bakker, and R. H. Drent. 2006. Surfing on a green wave: how plant growth drives spring migration in the barnacle goose Branta leucopsis. Ardea 94: 567-577.

Van Moorter, B., D. Visscher, S. Benhamou, L. Borger, M. S. Boyce, and J.-M. Gaillard. 2009. Memory keeps you at home: a mechanistic model for home range emergence. Oikos 118:641-652.

van Wijk, R. E., A. Kölzsch, H. Kruckenberg, B. S. Ebbinge, G. J. D. M. Müskens, and B. A. Nolet. 2012. Individually tracked geese follow peaks of temperature acceleration during spring migration. Oikos 121:655-664.

Voeten, M. M., C. van de Vijver, H. Olff, and F. van Langevelde. 2010. Possible causes of decreasing migratory ungulate populations in an east African savannah after restrictions in their seasonal movements. African Journal of Ecology 48:169-179.

Walli, A., S. L. H. Teo, A. Boustany, C. J. Farwell, T. Williams, H. Dewar, E. Prince, and B. A. Block. 2009. Seasonal movements, aggregations and diving behavior of Atlantic bluefin tuna (Thunnus thynnus) revealed with archival tags. PLoS ONE 4:e6151.

Wallin, E., and P. Milberg. 1995. Effect of bean geese (Anser fabalis) grazing on winter wheat during migration stopover in southern Sweden. Agriculture, Ecosystems and Environment 54:103-108.

Wang, T. J., A. K. Skidmore, Z. G. Zeng, P. S. A. Beck, Y. L. Si, Y. L. Song, X. H. Liu, and H. T. Prins. 2010. Migration patterns of two endangered sympatric species from a remote sensing perspective. Photogrammetric Engineering and Remote Sensing 76: 1343-1352.

Warnock, N., and M. A. Bishop. 1998. Spring stopover ecology of migrant western sandpipers. Condor 100:456-467.

White, R. G. 1983. Foraging patterns and their multiplier effects on productivity of northern ungulates. Oikos 40:377-384.

Wikelski, M., D. Moskowitz, J. S. Adelman, J. Cochran, D. S. Wilcove, and M. L. May. 2006. Simple rules guide dragonfly migration. Biology Letters 2:325-329.

Yong, W., D. M. Finch, F. R. Moore, and J. F. Kelly. 1998. Stopover ecology and habitat use of migratory Wilson's warblers. Auk 115: $829-842$.

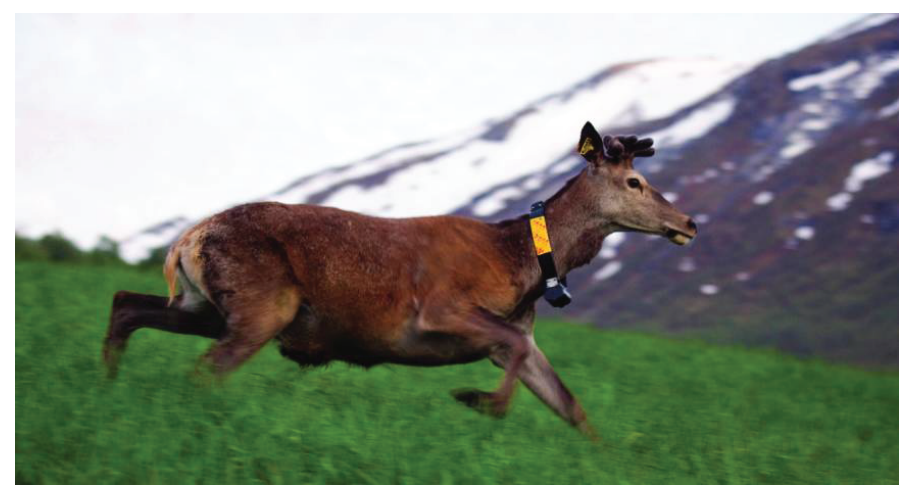

Norwegian red deer male equipped with a GPS collar. Photograph by Johan Trygve Solheim. 


\title{
Appendix A from R. Bischof et al., "A Migratory Northern Ungulate in the Pursuit of Spring: Jumping or Surfing the Green Wave?"
}

\author{
(Am. Nat., vol. 180, no. 4, p. 000)
}

\author{
Preparation of NDVI Time Series \\ NDVI Extraction
}

We obtained NDVI data layers covering all of Norway (tiles h18v02 and h18v03) for the entire period of our study (2002-2010). These images are composed of $250 \times 250$-m pixels with a 16-day temporal resolution and are made available by NASA at a dedicated FTP site (ftp://e4ft101.cr.usgs.gov/MOLT/MOD13Q1.005/). Tiles for each separate 16day period were merged and subsampled to a rectangular area containing all study regions with the MODIS reprojection tool, version 4.0 (https://lpdaac.usgs.gov/lpdaac/tools/modis_reprojection_tool). Next, we overlaid NDVI rasters with red deer GPS relocations and extracted NDVI and pixel-quality values for each pixel $(N=76,344)$ that contained at least one red deer relocation. This process was repeated for NDVI tiles associated with every 16-day period from the period 2002-2010, resulting in a 9-year raw NDVI time series for each relocation pixel in our data set.

Although MODIS NDVI data are postprocessed by NASA to ensure quality and to reduce noise, because of various factors (atmospheric disturbance, snow and ice cover, sensor issues, measurement/interpretation errors) NDVI time series usually require additional noise reduction (typically a combination of filters and function fitting) to remove unrealistic data points or unreliable pixels (Pettorelli et al. 2005b; Hird and McDermid 2009). We employed the method developed by Beck et al. (2006), which performed best in a comparison of recent approaches (Hird and McDermid 2009). We first filtered raw NDVI data and then fitted a double-logistic function to each year's green-up period on each pixel's NDVI series.

\section{Cleanup and Smoothing}

We applied the following protocol for cleaning up raw NDVI time series (fig. A1):

1. Set NDVI pixel values with pixel quality codes less than 0 (no data) or greater than 2 (snow or ice) to missing values.

2. For each NDVI time series, extract an alternative time series that contains only NDVI values with pixel quality 0 or 1 (i.e., high-quality and useful lower-quality observations). All other NDVI values are set as missing values. The lower 0.025 quantile of each pixel's 9-year time series is then used as the winter NDVI, that is, lowest possible value for the time series. All remaining NDVI data below this value are set to the winter NDVI, as are any missing data points 65 days before or 60 days after the turn of the year (as these can reasonably be assumed to be days with little if any vegetation growth). This allowed us to set a winter baseline for each pixel (fig. A2).

3. For further noise reduction, apply a moving median filter (search window $=3$ ) to each NDVI time series (fig. A3).

We were interested in the relative shape of the NDVI time series, not absolute values; therefore, we scaled the processed NDVI time series to between 0 and 1 . We scaled by using the upper 0.925 quantile of each pixel's 9-year filtered time series. This brought the added benefit that we did not have to estimate an asymptote parameter during nonlinear function fitting and some additional adjustment to the upper envelope. The latter has previously been recommended, because most noise in the NDVI is negatively biased (Jonsson and Eklundh 2004). 


\section{Raw NDVI data}

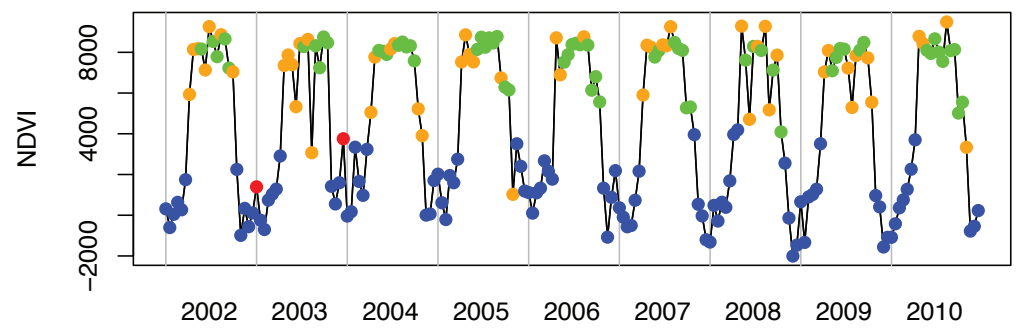

Figure A1: Illustration of raw normalized difference vegetation index (NDVI) time series for one pixel. The color of each circle corresponds to the pixel reliability value: high-quality values in green, useful lower-quality values in orange, snow or ice cover in blue, useless observations in red.

\section{Baseline set to winter NDVI}

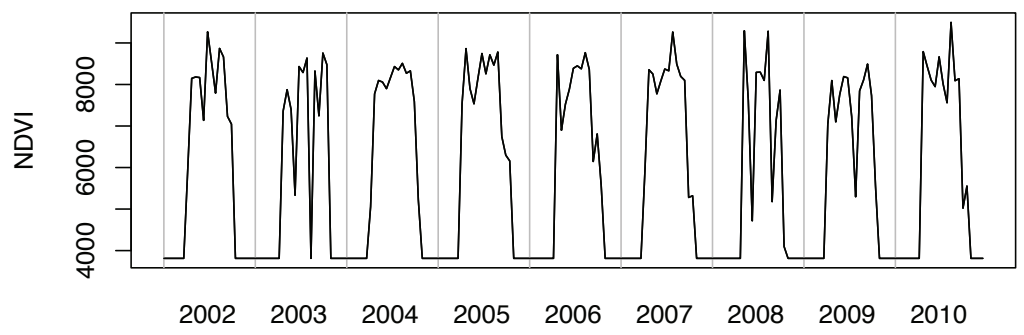

Figure A2: Illustration of normalized difference vegetation index (NDVI) data with winter baseline for the pixel used in figure A1.

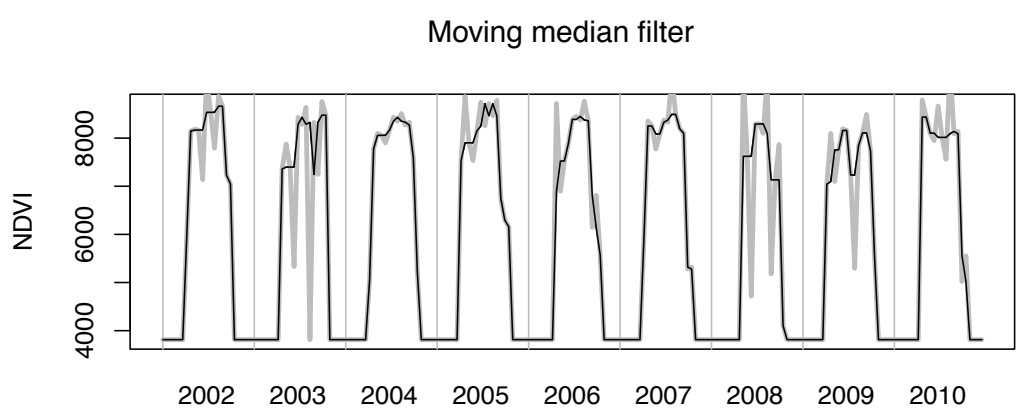

Figure A3: Illustration of the filtered normalized difference vegetation index (NDVI) data for the pixel used in figure A1. The raw values that are set to the winter baseline are shown in gray (fig. A2); values filtered with a median filter are shown in black. 


\section{Double-Logistic Curve Fitting}

For curve fitting, we picked the double-logistic function over other alternative approaches, because (1) it, together with the asymmetric Gaussian, had been shown to be superior with respect to overall noise reduction and maintenance of data integrity when fitted to full-year NDVI time series (Beck et al. 2006; Hird and McDermid 2009) and (2) it simplified the extraction of our measure of springness (see below). We fitted the double-logistic function to the scaled (0-1) annual NDVI profile:

$$
\operatorname{NDVI}(t)=\frac{1}{1+\exp \left(\left(\operatorname{xmid} S_{\mathrm{NDVI}}-t\right) / \mathrm{scal} S_{\mathrm{NDVI}}\right)}-\frac{1}{1+\exp \left(\left(x \operatorname{xmid} A_{\mathrm{NDVI}}-t\right) / \mathrm{scal} A_{\mathrm{NDVI}}\right)} .
$$

Here, $x$ mid $S_{\mathrm{NDVI}}$ represents the inflection point and scal $S_{\mathrm{NDVI}}$ the scale parameter for the spring green-up portion of the NDVI curve; xmid $A_{\mathrm{NDVI}}$ and $\mathrm{scal} A_{\mathrm{NDVI}}$ are the equivalent parameters for the fall dry-down. We used the nls function (Pinheiro et al. 2009) in R to fit this curve to the annual NDVI profile associated with each pixel (fig. A4).

\section{Fitted double logistic}

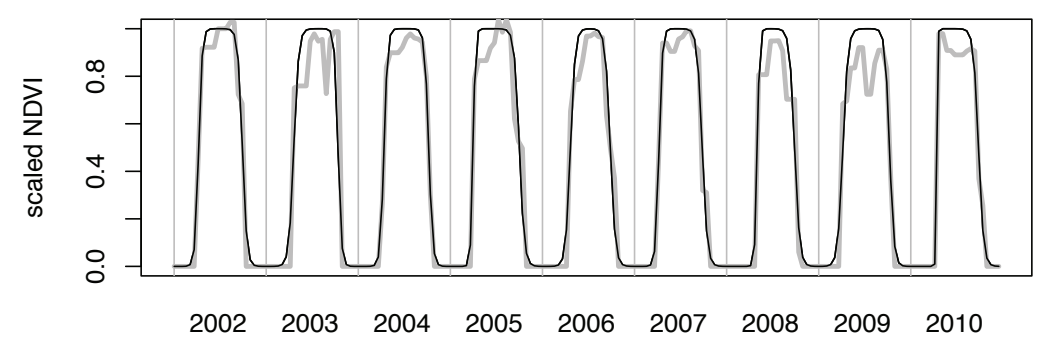

Figure A4: Illustration of the fitted normalized difference vegetation index (NDVI) data for the pixel used in figure A1. The filtered values from the median filter are shown in gray (fig. A3); the double-logistic curve fitted to those values is overlaid in black.

\section{Calculating Springness}

Since the NDVI is a measure of green biomass in a given pixel, the change in the NDVI over time provides a measure of the rate of change in green biomass, that is, the rate of increase in photosynthetic activity (Hird and McDermid 2009). For example, the rate at which new vegetation is emerging should be highest where the NDVI slope is steepest. Hird and McDermid (2009) used the maximum increase in the NDVI between two successive composite periods to define maximum green-up, but for the green-up portion of equation (A1), this instantaneous rate of green-up (IRG) can be obtained deterministically by taking its first derivative $d$ NDVI/dt (solid line in fig. 3):

$$
\operatorname{IRG}(t)=\frac{\exp \left(\left(t+\operatorname{xmid} S_{\mathrm{NDVI}}\right) / \mathrm{scal} S_{\mathrm{NDVI}}\right)}{2 \mathrm{scal} S_{\mathrm{NDVI}} e^{\left(t+\mathrm{xmid} S_{\mathrm{NDVI}}\right) / \mathrm{scal} S_{\mathrm{NDVI}}}+\operatorname{scal} S_{\mathrm{NDVI}} e^{2 t / \mathrm{scal} S}+\operatorname{scal} S_{\mathrm{NDVI}} e^{2 \mathrm{xmid} S_{\mathrm{NDVI}} / \mathrm{scal}_{\mathrm{NDVI}}}} .
$$

\section{Literature Cited Only in Appendix A}

Jonsson, P., and L. Eklundh. 2004. TIMESAT: a program for analyzing time-series of satellite sensor data. Computers and Geosciences 30:833-845.

Pinheiro, J., D. Bates, S. DebRoy, D. Sarkar, and R Development Core Team. 2009. nlme: linear and nonlinear mixed effects models. R package, version 3.1-96. http://cran.r-project.org/web/packages/nlme/. 


\section{Appendix B from R. Bischof et al., "A migratory northern ungulate in the pursuit of spring:}

jumping or surfing the green wave?"

(Am. Nat. 2012. Vol. 180)

\section{Supplemental figures and tables}

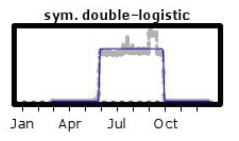

asym. double.logistic
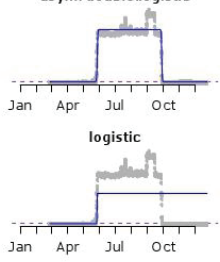

simple linear

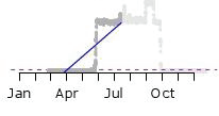

intercept

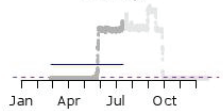

A

migratory
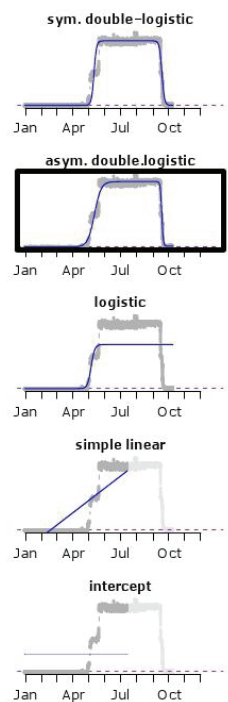

B

migratory

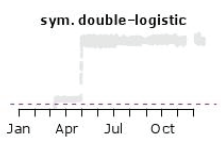

asym. double.logistic
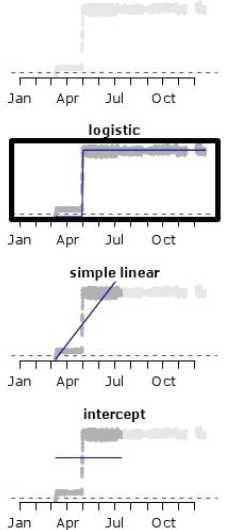

C

dispersing

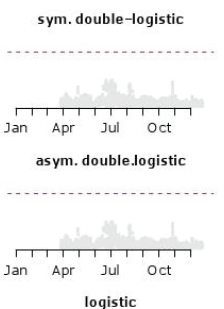

sym. double-logistic

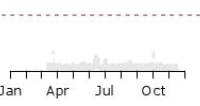

asym. double.logistic
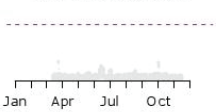

logistic

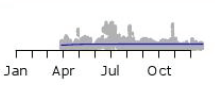

simple linear

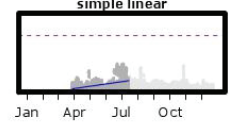

intercept

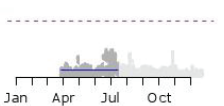

D

resident

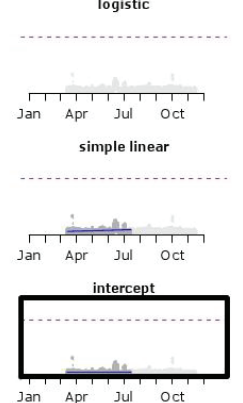

$\mathbf{E}$

resident

Figure B1. Example of space-use categories identified using the automated approach by (Bunnefeld et al. 2011) on red deer net-squared displacement (NSD, y-axis, not shown) profiles (gray time series). Each column is associated with a different individual's annual GPS data, with the space-use category designation indicated below. An attempt was made to fit 5 different functions (blue lines, details in Bunnefeld et al. 2011) to each NSD profile (from top to bottom): symmetrical double logistic, asymmetrical double logistic, logistic, simple linear, and intercept-only. The best-fitting model was selected based on AIC value and we added additional criteria to make the space-use designation. For migratory: minimum distance between summer and winter range had to be at least $3 \mathrm{~km}$, fall migration had to return within $3 \mathrm{~km}$ (purple dashed line) of point of origin, spring migration had to take place before Jul 15. For resident: non-linear fitted functions (in case they fit better than simple linear or intercept models) had to remain within $3 \mathrm{~km}$ of the point of origin, simple linear model (in case it fit better than 
the other models) had to have a slope $<15.4 \mathrm{~m} /$ day. Cases were considered incomplete if the animal moved away from the winter area during spring migration, but monitoring ended before Nov 1, without a registered return to the winter area. Sub-categories «incomplete», «dispersal», and «ambiguous»/«irregular» were pooled as «other». AIC comparisons were made for models fit to the same data, but (upon selection of the top model) simple linear or intercept models were refit to the subset of the data between Jan 1 to Jul 15 (marked darker gray in the NSD time series) to exclude artifacts as a result of fall excursions during the latter part of the year.
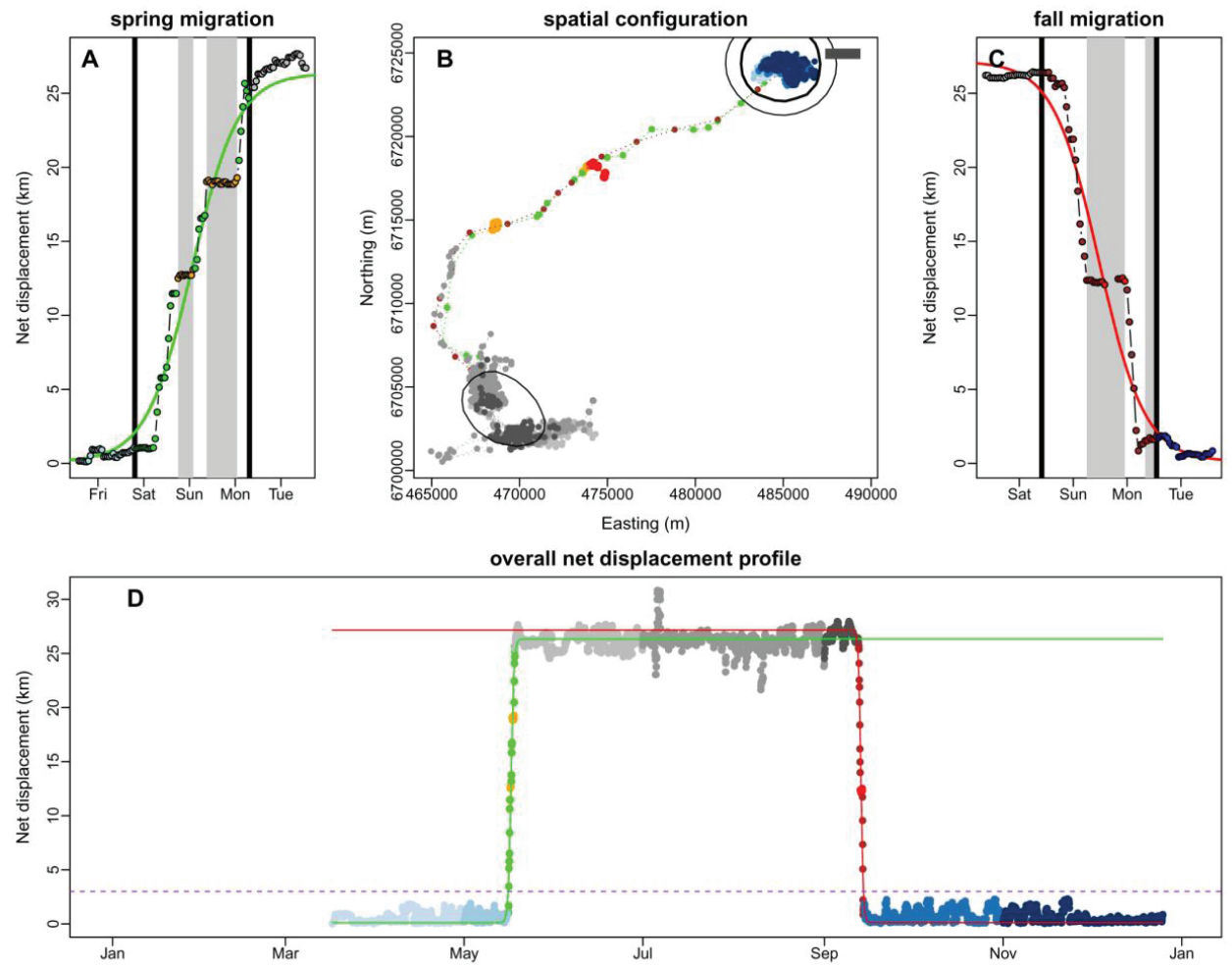

Figure B2. Migratory red deer. Four plots give a visual overview of the spatio-temporal configuration of an individual red deer's GPS re-locations. zoomed-in spring migration segment of the net displacement (ND) profile (A), spatial layout of re-locations with $2 \mathrm{~km}$ scale bar in the top right corner (B), zoomed-in fall migration segment of the ND profile (C), and complete ND profile (D). We used ND because we did not have a need to place disproportionate weight on displacements farther from the point of origin as is done with net-squared displacement (NSD, Bunnefeld et al. 2011). Individual relocations are color-coded in all plots to be identifiable as winter range (darkening shades of blue), spring migration (green), summer range (darkening shades of gray), 
fall migration (brown). Relocations within stopover sites (see main text for approach for identifying stopovers) are colored orange. Gray bars in the spring and fall migration frames show the timing and duration of stopover sites in the ND profile (zoomed). Logistic curves fitted to the spring (green line) and fall migration (red line) of the ND profile follow the equation $\operatorname{Fit}(\mathrm{t})=\frac{\mathrm{Asym}_{\mathrm{ND}}}{1+\exp \left(\left(\mathrm{xmid}_{\mathrm{ND}}-\mathrm{t}\right) / \mathrm{scal}_{\mathrm{ND}}\right)}$ The function parameters Asym $_{N D}, x \operatorname{sid}_{N D}$,

and $\operatorname{scal}_{N D}$ represent, respectively, the distance migrated, the date of mid-migration, and the scale parameter (a measure of the speed of migration). From these, we calculated the starting and ending points of migration as $\operatorname{xmid}_{N D}-2.5 \mathrm{scal}_{N D}$ and $\mathrm{xmid}_{N D}+2.5 \mathrm{scal}_{N D}$, respectively. The purple dashed line represents the $3 \mathrm{~km}$ cut-off from the point of origin (see also figure B1). Kernel density contours are displayed as thick (25\%) and thin $(50 \%)$ black lines in the map (B).
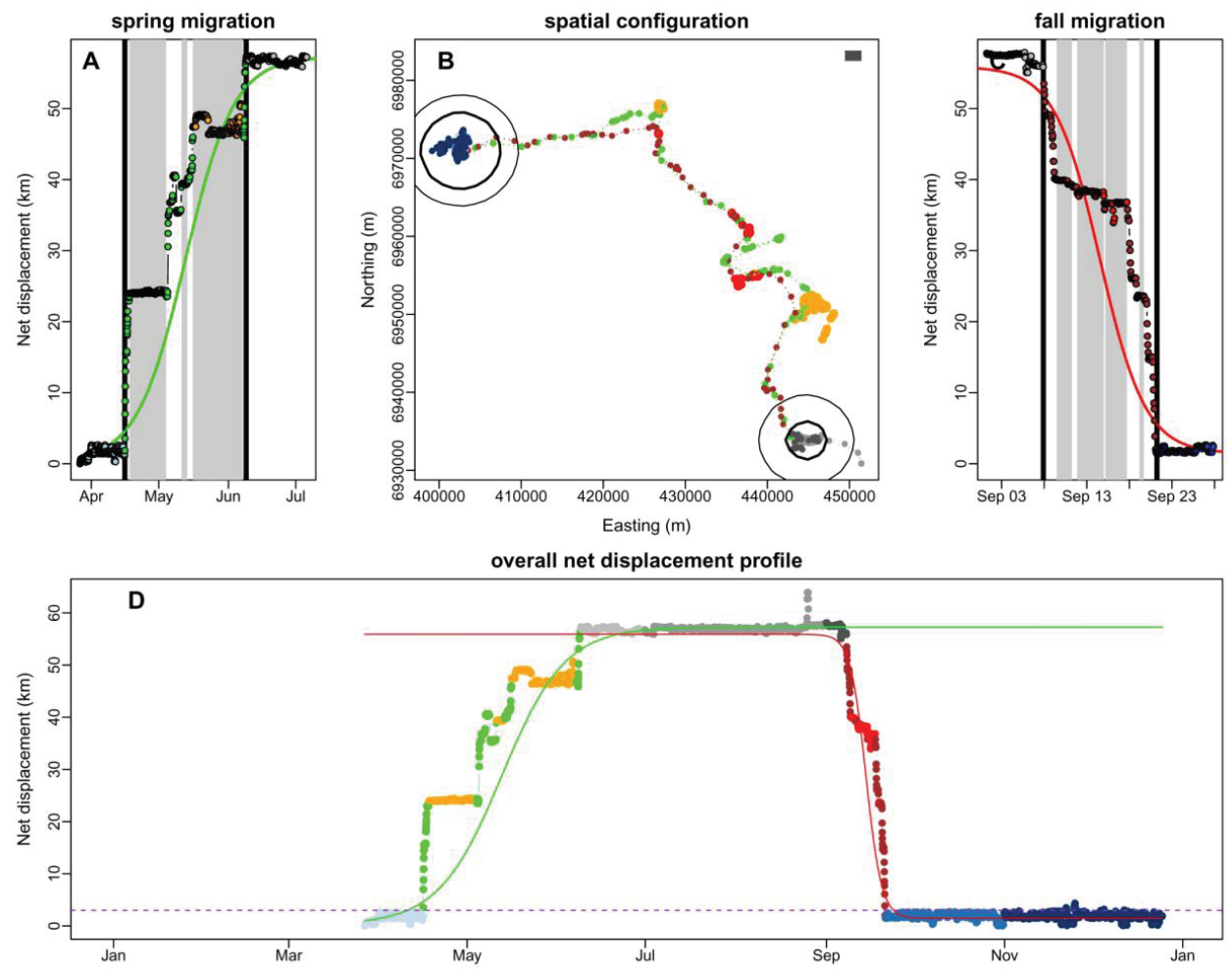

Figure B3. Migratory red deer with extended stopovers during spring migration. 

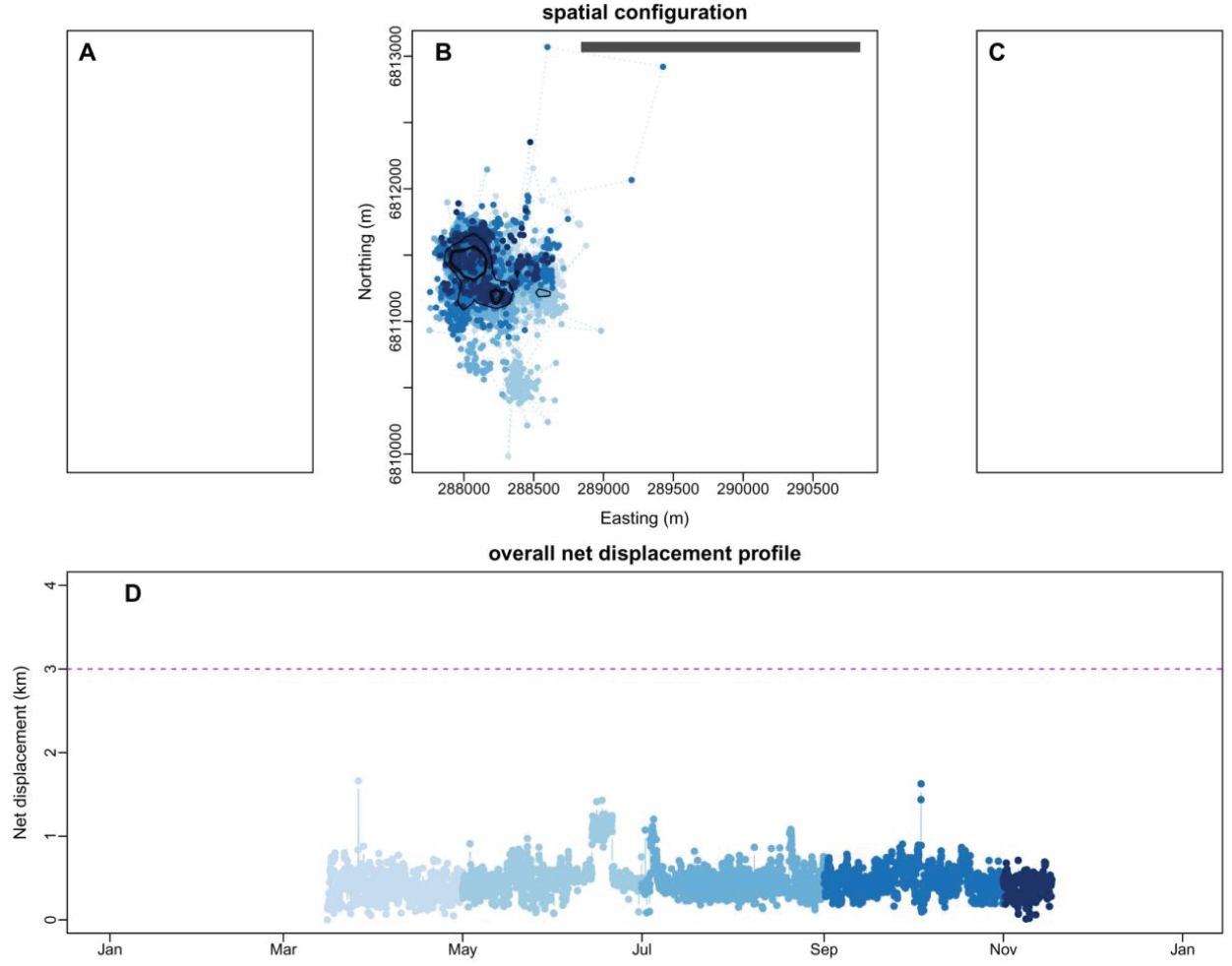

Figure B4. Resident red deer. 

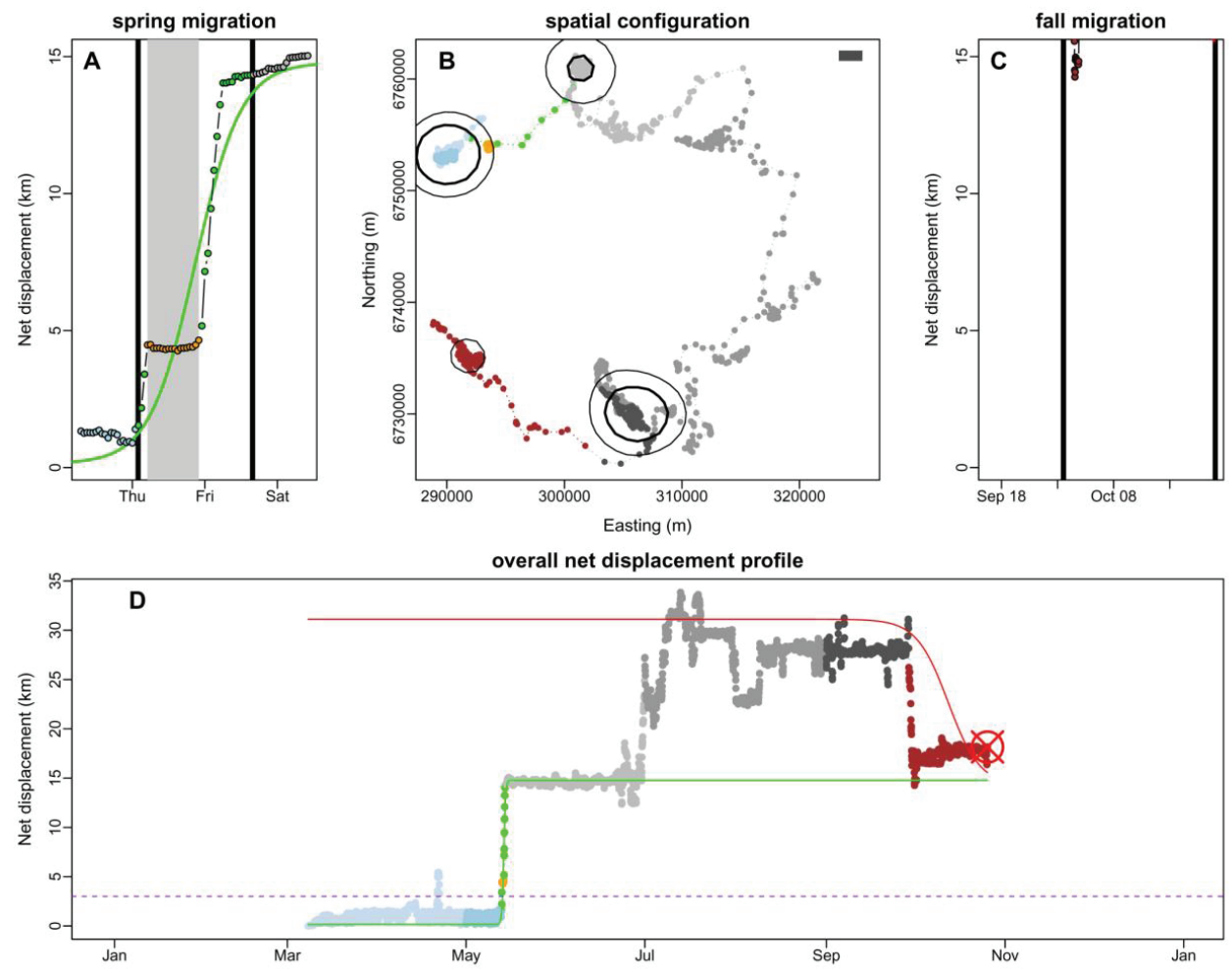

Figure B5. Incomplete re-location set, classified as "other" in the analysis. The animal was killed during the autumn hunt (red crossed-out circle) before a return to the pre-migration area could be registered and before the cutoff of for designation as dispersal (Nov 1). 

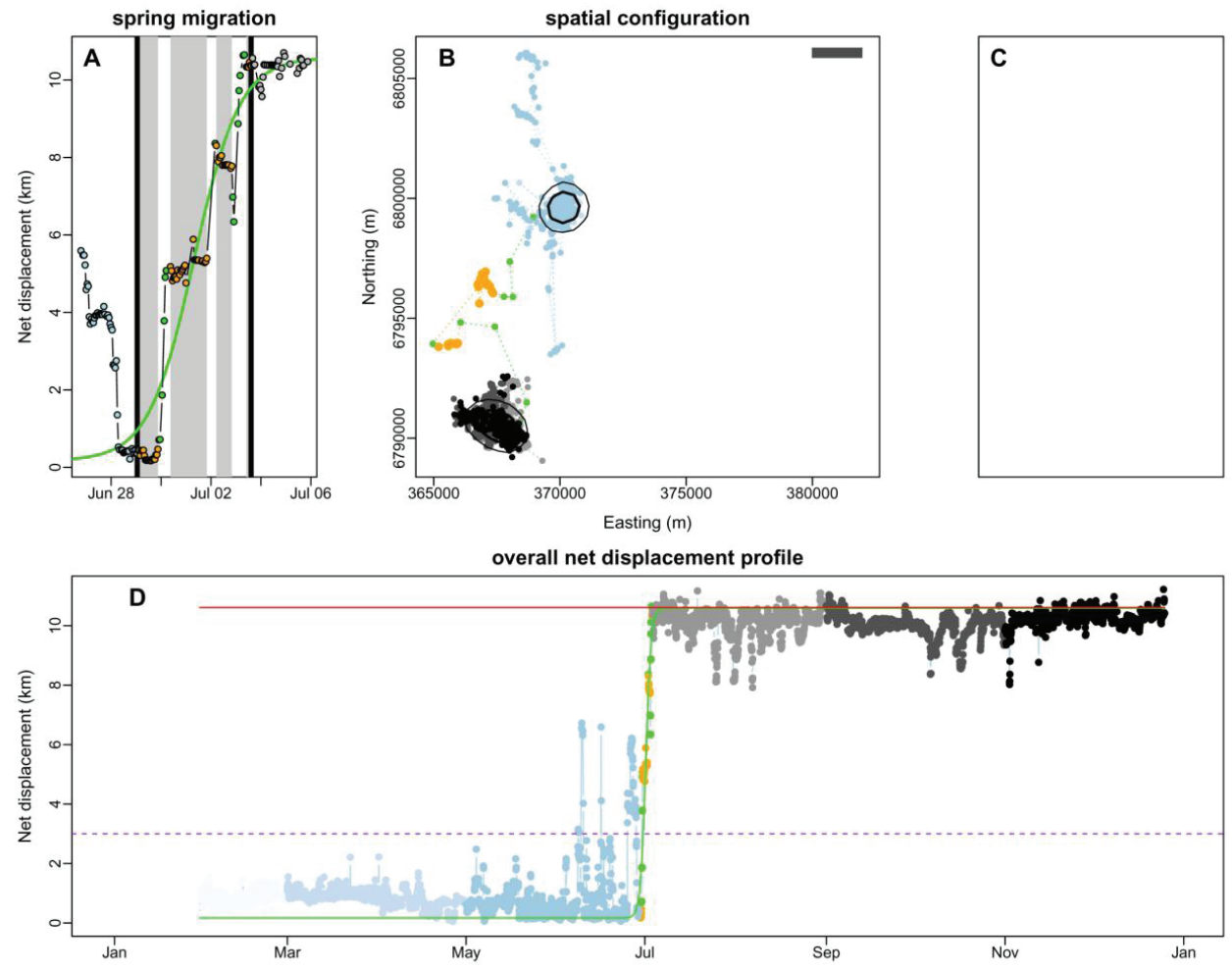

Figure B6. Dispersal, classified as "other" in the analysis. 

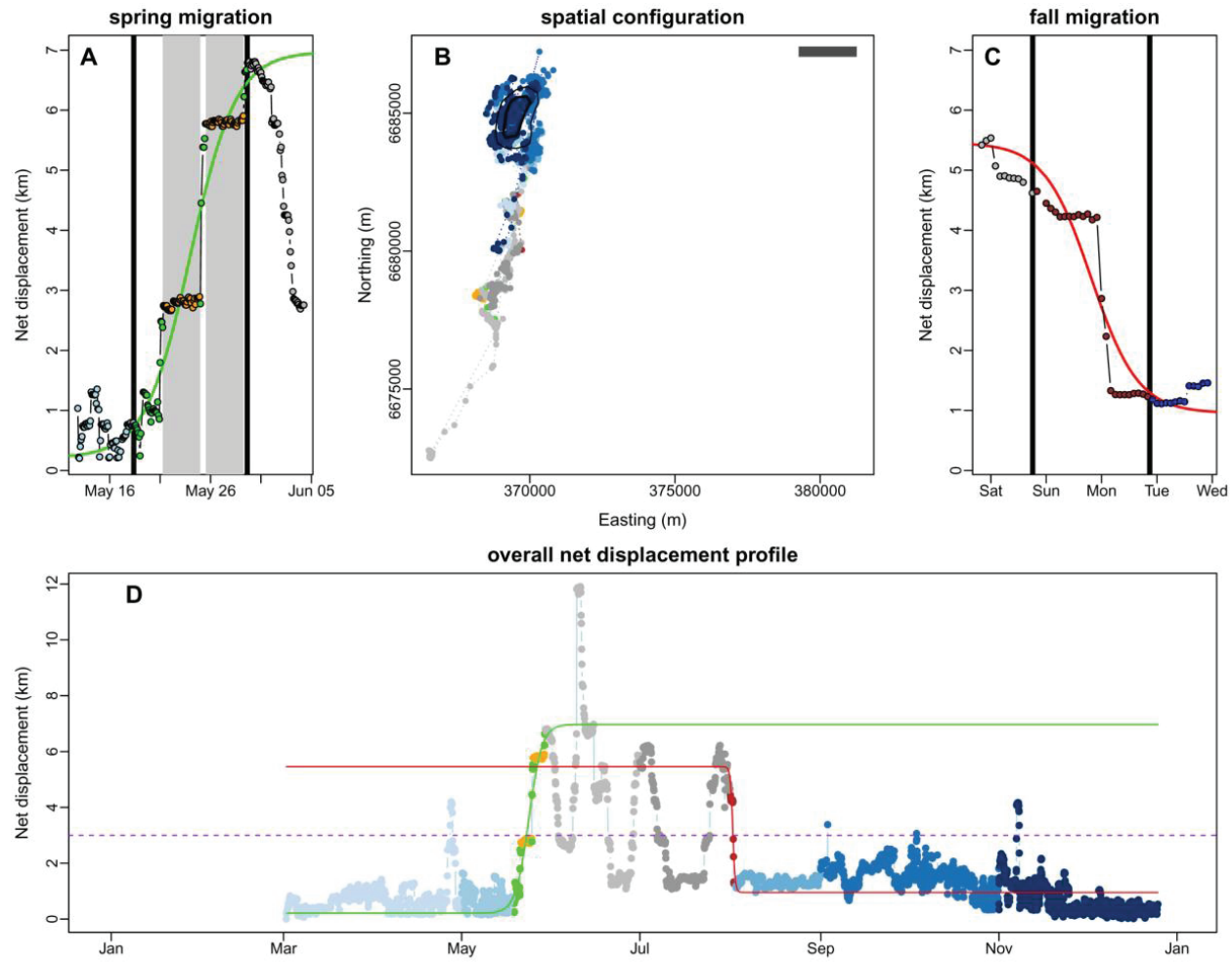

Figure B7. Irregular, classified as "other" in the analysis. 
Table B8: Results from a mixed effects linear regressions (separate for males and females) predicting the difference between median date of peak IRG at the summer range and the winter range of migratory red deer in 7 different study regions in Norway. Individual ID and year (2002-2010) were included in the models as crossed random effects. One level $(\mathrm{N})$ of region serves as a contrast $(\beta=0)$ for the remaining levels.

\begin{tabular}{|c|c|c|c|c|c|}
\hline & Predictor & $\beta$ & $S E$ & $t$ & $\operatorname{Pr}(>|t|)$ \\
\hline \multirow[t]{9}{*}{ Females } & Intercept & 16.906 & 5.628 & 3.004 & 0.003 \\
\hline & Region & & & & \\
\hline & $\mathrm{N}$ & 0.000 & & & \\
\hline & NW & 10.627 & 6.829 & 1.556 & 0.122 \\
\hline & W & 17.814 & 6.496 & 2.742 & 0.007 \\
\hline & SW & -2.149 & 7.213 & -0.298 & 0.766 \\
\hline & S & -0.799 & 7.877 & -0.102 & 0.919 \\
\hline & SE & 1.718 & 7.129 & 0.241 & 0.810 \\
\hline & E & -5.271 & 7.339 & -0.718 & 0.474 \\
\hline \multirow[t]{8}{*}{ Males } & Intercept & 15.188 & 4.657 & 3.261 & 0.002 \\
\hline & Region & & & & \\
\hline & $\mathrm{N}$ & 0.000 & & & \\
\hline & NW & 2.534 & 6.316 & 0.401 & 0.690 \\
\hline & W & 15.650 & 11.045 & 1.417 & 0.163 \\
\hline & SW & 15.704 & 7.003 & 2.243 & 0.030 \\
\hline & $\mathrm{S}$ & 67.216 & 17.960 & 3.742 & $<0.001$ \\
\hline & SE & -4.122 & 17.960 & -0.229 & 0.820 \\
\hline
\end{tabular}


Table B9. Results from a mixed effects linear regressions predicting the cumulative instantaneous rate of green-up (CIRG, cumulative spring), experienced by male and female red deer in Norway. Region and year (2002-2010) were included in the models as crossed random effects, individual ID as nested in region. One level of each categorical variable serves as a contrast $(\beta=0)$ for the remaining levels of that variable.

\begin{tabular}{|c|c|c|c|c|c|}
\hline & Predictor & $\beta$ & $S E$ & $t$ & $\operatorname{Pr}(>|t|)$ \\
\hline \multirow[t]{3}{*}{ Females } & $\begin{array}{l}\text { Intercept } \\
\text { space-use category } \\
\text { migratory }\end{array}$ & 0 & 2.880 & 15.355 & $<0.001$ \\
\hline & resident & -8.737 & 1.607 & -5.436 & $<0.001$ \\
\hline & density & -3.613 & 1.439 & -2.511 & 0.013 \\
\hline \multirow[t]{5}{*}{ Males } & $\begin{array}{l}\text { Intercept } \\
\text { space-use category } \\
\text { migratory }\end{array}$ & 23.154 & 10.213 & 2.267 & 0.027 \\
\hline & resident & 18.258 & 10.851 & 1.683 & 0.098 \\
\hline & & -4.616 & 2.558 & -1.805 & 0.076 \\
\hline & $\begin{array}{l}\text { topographic diversity } \\
\text { space-use cat : topogr. div. } \\
\text { migratory }\end{array}$ & 14.268 & 5.294 & 2.695 & 0.009 \\
\hline & resident & -14.591 & 7.074 & -2.063 & 0.044 \\
\hline
\end{tabular}



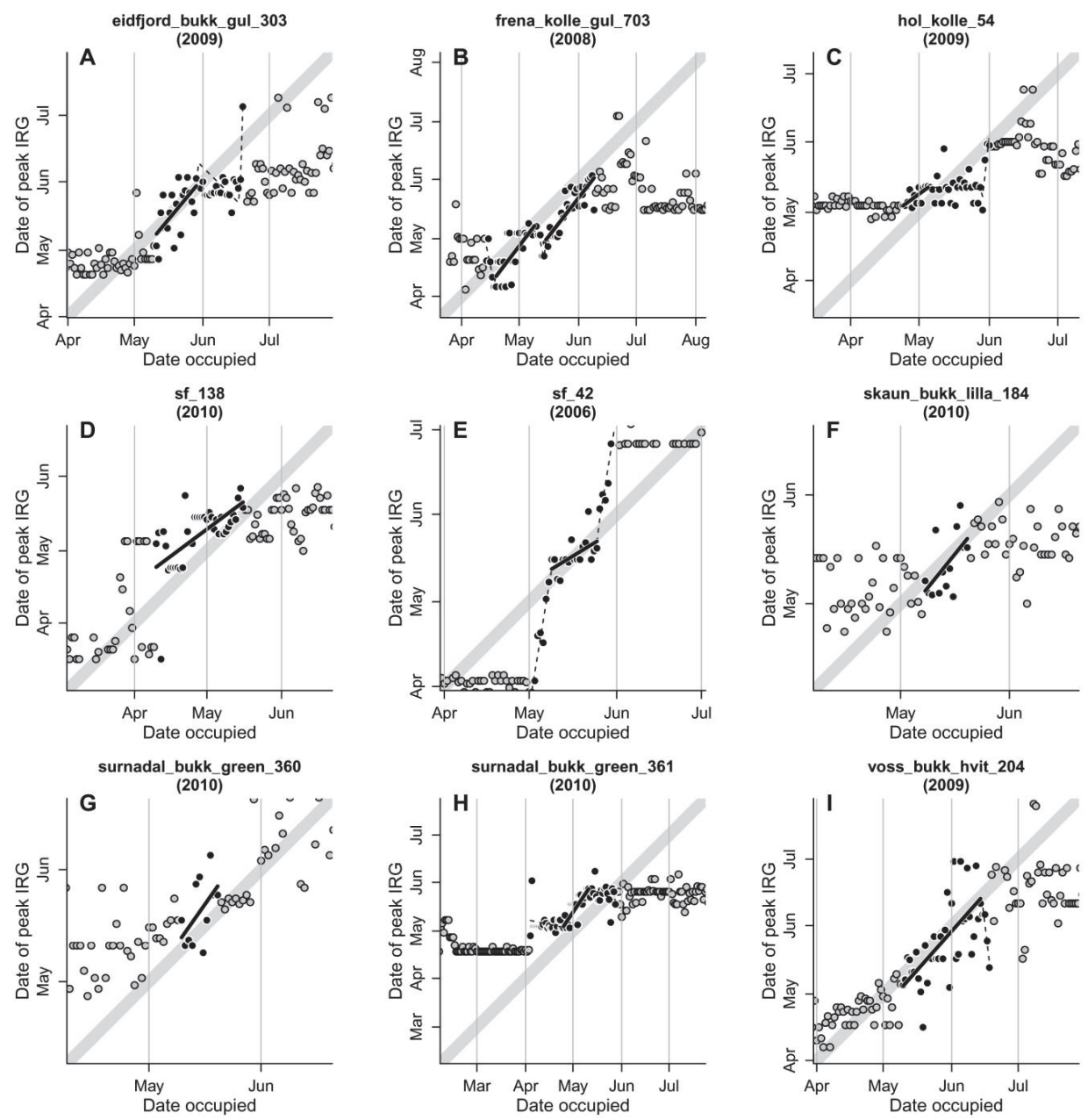

Figure B10: Green wave pursuit patterns of 9 Norwegian red deer identified as surfing the green wave during migration. Plots show the relationship between the date of peak instantaneous green-up at a given location and the date at which that location was occupied (black dots: spring migration period, grey dots: summer and winter range). The diagonal (thick gray line) represents the leading edge of the green wave and data points on the line are indicative of locations occupied at the time of their peak rate of green-up. Dashed lines in each plot show the fit of regression models (segmented or logistic, breakpoints selected based on AIC), surfing segments are marked with thick black lines. 


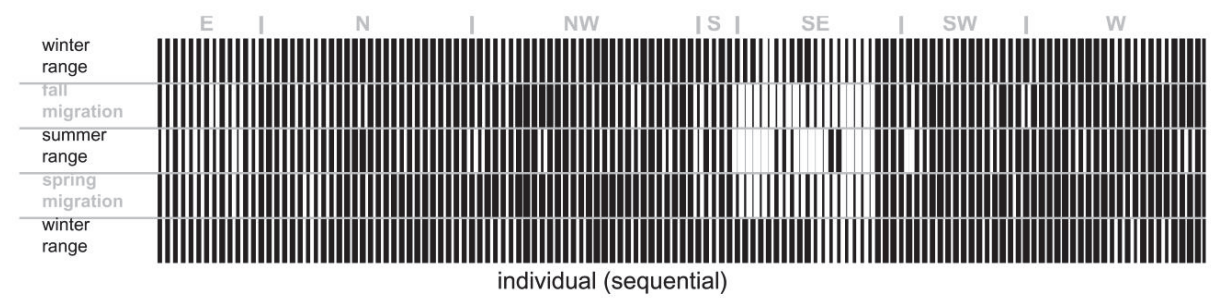

Figure B11: Comparison of habitat suitability associated with seasonal ranges and migration corridors of individual Norwegian red deer monitored between 2002-2010, in 7 different regions. Each vertical line represents the annual pattern of habitat suitability experienced by an individual red deer moving (bottom to top) from its winter range to its summer range, and back. Relative suitability is represented by the thickness of the line, with thicker lines representing a higher suitability index than thin lines. Habitat suitability was extracted for each re-location (typically every 1-2 hours) from a Norwegian red deer habitat suitability map (100m resolution, Loe et al. 2012), suitability was than pooled over days (in order to reduce potential biases associated with an uneven number of relocations per day) and averaged for each region. Suitability estimates associated with spring migration relocations were intermediate between suitability at the winter range (highest, $\beta_{\text {winter.vs.spring }}=0.25, \mathrm{SE}$ $=0.15, \mathrm{t}=1.67, \mathrm{p}=0.096$, trend only) and the summer range (lowest, $\beta_{\text {summer.vs.spring }}=-0.807, \mathrm{SE}=0.15, \mathrm{t}=$ $5.395, \mathrm{p}<0.001)$, suggesting that migratory deer are not simply forced to "jump" across unsuitable habitat between their main seasonal ranges.

\section{Literature cited}

Bunnefeld, N., L. Borger, B. van Moorter, C. M. Rolandsen, H. Dettki, E. J. Solberg, and G. Ericsson. 2011. A model-driven approach to quantify migration patterns: individual, regional and yearly differences. Journal of Animal Ecology 80:466-476.

Loe, L. E., C. Bonenfant, E. L. Meisingset, and A. Mysterud. 2012. Effects of spatial scale and sample size in GPS-based species distribution models: are the best models trivial for red deer management? European Journal of Wildlife Research 58:195-203. 